\title{
The spatial diffusion of fertility decline in Egypt (1950-2006)
}

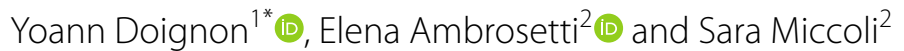

*Correspondence:
yoann.doignon@uclouvain.
be
${ }^{1}$ Centre for Demographic
Research, UCLouvain,
Institute for the Analysis
of Change in Contemporary
and Historical Societies,
1, Place Montesquieu,
Boîte L2.08.03,
1348 Louvain-la-Neuve,
Belgium
Full list of author information
is available at the end of the
article

*Correspondence:

yoann.doignon@uclouvain. be

Research, UCLouvain, Institute for the Analysis of Change in Contemporary and Historical Societies squieu, Belgium

is available at the end of the article

\begin{abstract}
While the Egyptian fertility transition has been widely addressed in the literature, few researches have studied the spatial dimension of fertility. Using population census data, the aim of this study is to describe and measure the evolution of the geography of fertility on a subnational scale (qism/markaz), focusing on the period between 1960 and 2006. We assumed that the decline in fertility had spread spatially through Egypt, the spatial diffusion occurring through two traditional mechanisms: contagion and hierarchical diffusion. Our results confirm our hypotheses and highlight the importance of studying the spatial diffusion of the fertility transition. This study is unique for the Egyptian context given the long period and fine territorial scale considered. Our study constitutes an important addition to the existing group of studies on the spatial diffusion of fertility. Finally, it contributes to gaining further insight into a demographic dynamic which is fundamental for the future of Egypt.
\end{abstract}

Keywords: Spatial diffusion, Fertility decline, Egypt, Spatial pattern, Spatial autocorrelation

\section{Introduction}

The population of Egypt more than tripled between 1960 and 2020, registering an increase from 27 million to about 100 million inhabitants. More than $95 \%$ of its territory consists of deserts. Its population is concentrated along the Nile, the narrow, fertile strip that runs from southern Egypt (Upper Egypt) to the north (Lower Egypt) over a distance of $1800 \mathrm{~km}$. The population density of the entire country is 90 inhabitants per square kilometre, but the figure rises to 1140 inhabitants per square kilometre taking into account only the populated areas. Despite very rapid urbanization in the twentieth century, mainly benefiting the Cairo agglomeration, Alexandria and a dozen major cities, mostly in the Nile delta, Egypt is still predominantly rural. ${ }^{1}$

The total fertility rate (TFR) in Egypt has declined progressively since the early 1960s when it was about 6.7 children per woman (Fig. 1). However, the decline showed an erratic trend until the mid-1980s, when the fertility transition finally started. Fertility continued to decline until the mid-1990s. Between 1995 and 2008 the

\footnotetext{
${ }^{1}$ According to the UN definition. We should clarify that Egypt's urbanization rate depends on the definition chosen. Egypt is an emblematic example because the rural areas are very densely populated: the large villages come close to cities in terms of population.
} priate credit to the original author(s) and the source, provide a link to the Creative Commons licence, and indicate if changes were made. The images or other third party material in this article are included in the article's Creative Commons licence, unless indicated otherwise in a credit line to the material. If material is not included in the article's Creative Commons licence and your intended use is not permitted by statutory regulation or exceeds the permitted use, you will need to obtain permission directly from the copyright holder. To view a copy of this licence, visit http://creativecommons.org/licenses/by/4.0/. 


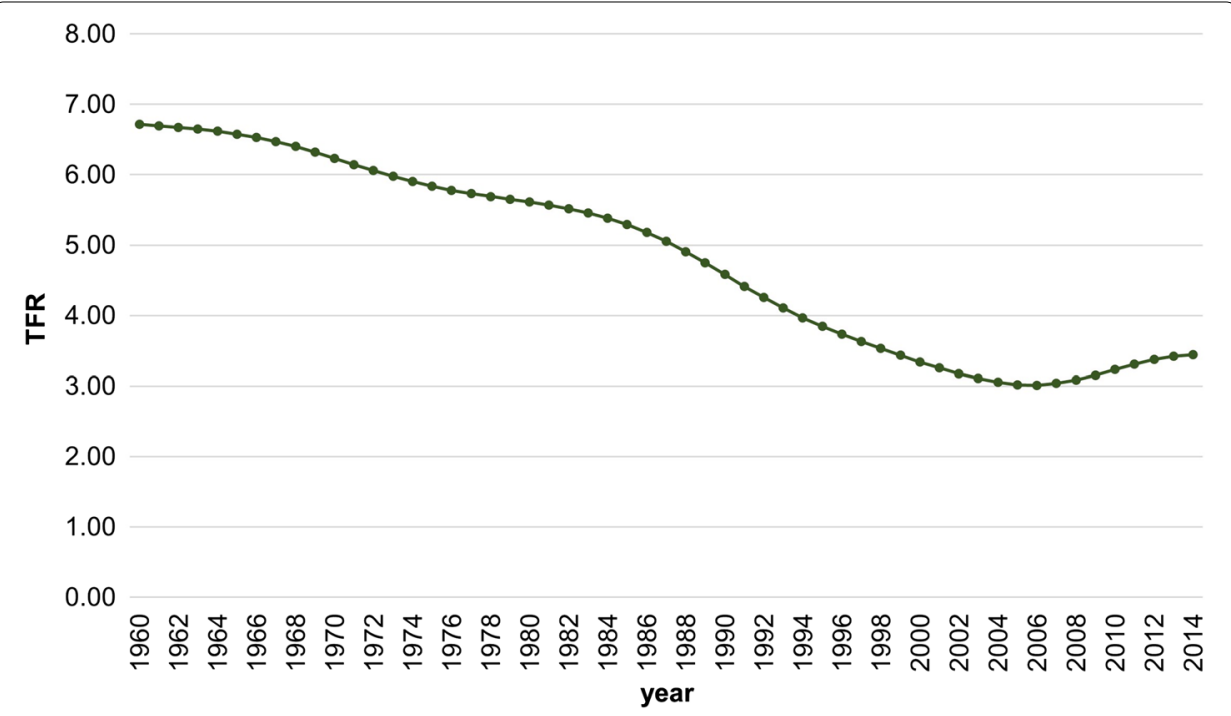

Fig. 1 TFR trends in Egypt 1960-2014. Sources: DHS (various years for the data from 1988 to 2014) and EFS for the data from 1960 to 1980

TFR slowly declined from 3.6 to 3 children per woman. Fertility is singled out as the main cause of the strong demographic growth that the country is witnessing. Indeed, the latest official estimate of the fertility rate was 3.5 children per woman in 2014; in contrast with the slow decrease and stability of the previous decades at the level of 3 children per woman, fertility has risen since 2008. According to the recent literature, the reversal in fertility since the mid-2000s is a consequence of the precarious economic situation that Egypt is facing. For instance, Courbage (2015a) stressed that the rise in fertility constitutes an over-investment in the future generation in terms of high numbers of children, i.e. a "poverty-driven transition" working the other way round. Krafft (2020) underlined that the increase in fertility is a consequence of the decline in the activity rate of educated women associated with the decline in employment opportunities for women, especially in the public sector. Thus, this marginalization in employment makes it less important for women to assess the opportunity cost of an additional birth.

Scholars trying to disentangle fertility transition in Egypt have offered several explanations. They have highlighted, among other aspects, the institutional context, religious traditionalism, the economic crisis and poverty, the political situation, the role of women in society, early marriage and health status (Al Zalak and Goujon, 2017; Ambrosetti, 2011, 2014; Caldwell, 1986; Courbage, 1999, 2015b; Fargues, 1997, 2003). As one of the few Arab countries whose demographic transition is still not fully completed despite an early decline in mortality, Ambrosetti (2011) showed that Egypt remains an exception in the rapidly evolving demographic landscape. The existence of family planning organizations, the relative tolerance of the religious authorities, the population policies in place and an open approach to the outside world are not sufficient to turn the tide. The reason for this resistance is to be found in the very foundations of Egyptian society-the importance of the family, the ideal number of 
children - and at the institutional level, in both the economic (labour market, growth) and sociocultural spheres. The importance of marriage, the role of education and the media, and the religious dimension are all powerful forces shaping individual behaviour. While consanguineous marriages have declined in prevalence since the 1980s, contraceptive use increased rapidly until the 2000s (Ambrosetti, 2011; Rashad, 2015; Rashad \& Zaky, 2014). Fertility rates by income groups converged during that period, having led to a narrowing of the fertility gradient by socioeconomic status. However, both age at marriage and the ideal number of children have remained virtually unchanged since the 1980s.

Although the Egyptian fertility transition has been widely addressed in the literature, there is a lack of research studying the spatial dimension of fertility. The few existing studies are limited to two classical oppositions: urban/rural and Lower/Upper Egypt. To the best of our knowledge, there is no study that provides an evolution of the fertility mapping at the local level for the whole country. In fact, there is currently hardly any information on the spatial pattern of fertility transition in this country, except that Cairo was the first territory to be affected by the decline in fertility, or that the transition has proved faster in the Nile delta than in its valley. Nevertheless, it is worth trying to understand the spatial distribution of fertility behaviours for two main reasons: first, because it would make it possible to precisely target areas where fertility level is still high with ad hoc policies. Currently, there is a family planning policy targeting specific territories. The policy introduced in 2017 by the Ministry of Social Solidarity is called Itnein Kifaya ("Two is enough") and is targeting rural areas where the fertility rate is particularly high (Awadalla, 2017). Second, our study on the trends in the spatial distribution of fertility Egypt over time will contribute to the strand of research on the spatial diffusion of the fertility transition. Our study is unique and original for the Egyptian context because it combines two dimensions: fine scale plus long time period. In fact, we aim to study fertility for a period of over 50 years (1950-2006) and to provide fertility estimates on the fine scale of qism/markaz, the second administrative level under governorates (Muhafaza) level, respectively, urban and rural areas. The combination of these two dimensions represents the ideal condition for studying spatial diffusion.

Our study is organized as follows: in the first section, we illustrate the background, i.e. the importance of taking into account space for a better understanding of fertility transition, and review the fertility transition in Egypt and the literature addressing this phenomenon. In the second section, we describe the data and methodology used. In the third section, we present the results, while the fourth section sets out the conclusions.

\section{Background and literature review}

\section{Fertility and geographical analysis}

Geography and space are key elements in the context of demographic phenomena and changes. All demographic events occur in specific spaces and geographical areas (Weeks, 2004). Geographical and spatial analyses offer a more detailed overview of some demographic dynamics and a clearer picture of the relations between specific variables and demographic changes at a detailed territorial level (De Castro, 2007). 
Several studies have focused on fertility trends, paying particular attention to the geographical context (Basten et al., 2012; Guilmoto \& Rajan, 2001; Vitali \& Billari, 2017; Weeks et al., 2000). In fact, knowledge and consideration of the territorial context, above all the local level, are crucial for an understanding of fertility patterns and convergences or divergences between different geographical areas (Schmertmann et al., 2008).

Space and fertility were associated in the study conducted by Princeton European Fertility Project, which aimed to analyse differences and similarities in the fertility transition of European provinces between the end of the nineteenth and mid-twentieth century (Coale \& Watkins, 1986; Watkins, 1991). The main findings of this study showed that contiguous territories and culturally homogeneous areas, such as those characterized by the same language or religion, went through similar trends in fertility. From the perspective of diffusion, fertility changes result not only from demographic, economic and social structures but also the diffusion of new ideas and attitudes towards children and parenthood (Casterline, 2001; Cleland \& Wilson, 1987; Schmertmann et al., 2008). However, this process can be of two types, social or geographical, or a combination of the two. In the first case, the diffusion of ideas and attitudes usually spreads through society from the top downwards. In the second case, changes spread through different areas following a spatial diffusion process (Bocquet-Appel \& Jakobi, 1998; Coale \& Watkins, 1986; Kurek \& Lange, 2012). In turn, the diffusion through space can develop through two processes: contagion or hierarchical processes (Bleha \& Durček, 2017; Lee et al., 2014; Saint-Julien, 2007). In the former case, the diffusion spreads across contiguous territories, in the latter, through a hierarchical structure, such as the urban structure (from the main cities to the small cities).

Together with ideas, attitudes and values, the spatial diffusion process also involves diffusion of policies and institutions (Vitali \& Billari, 2017). Various other researches on fertility decline show similar patterns of spatial diffusion and the important influence of neighbourhoods on the process (Bocquet-Appel \& Jakobi, 1998; Guilmoto \& Rajan, 2001; Potter et al., 2010; Vitali \& Billari, 2017).

As Schmertmann et al. (2008) pointed out, although social diffusion processes are relevant in explaining changes in fertility evolution, in many cases geographical contexts and diffusion through space seem to have a very strong influence. Territorial contexts entail demographic, economic, social structures, and also networks, policies, practices, languages and cultural values (Weeks, 2004). Therefore, geographical places and contexts contain a series of spatially clustered variables that can deeply influence reproductive behaviour. Differences in social, economic and cultural structures and contexts between geographical areas can contribute to shaping different fertility dynamics (Schmertmann et al., 2008; Weeks, 2004).

Observation of fertility differences over time in geographical areas has prompted many studies applying the geographical and spatial approach: spatial patterns of fertility decline in India (Guilmoto \& Rajan, 2001), in Brazil (Potter et al., 2010; Schmertmann et al., 2008) in Austria, Switzerland and Germany (Basten et al., 2012), in Belgium (Costa, 2015), in Prussia (Goldstein \& Klüsener, 2014), in Italy (Vitali \& Billari, 2017), in Spain (Sabater \& Graham, 2019) or in Sweden (Klüsener et al., 2019). These studies describe fertility trends and diversities at detailed territorial levels; furthermore, some seek to analyse the determinants of similarities and differences by considering the 


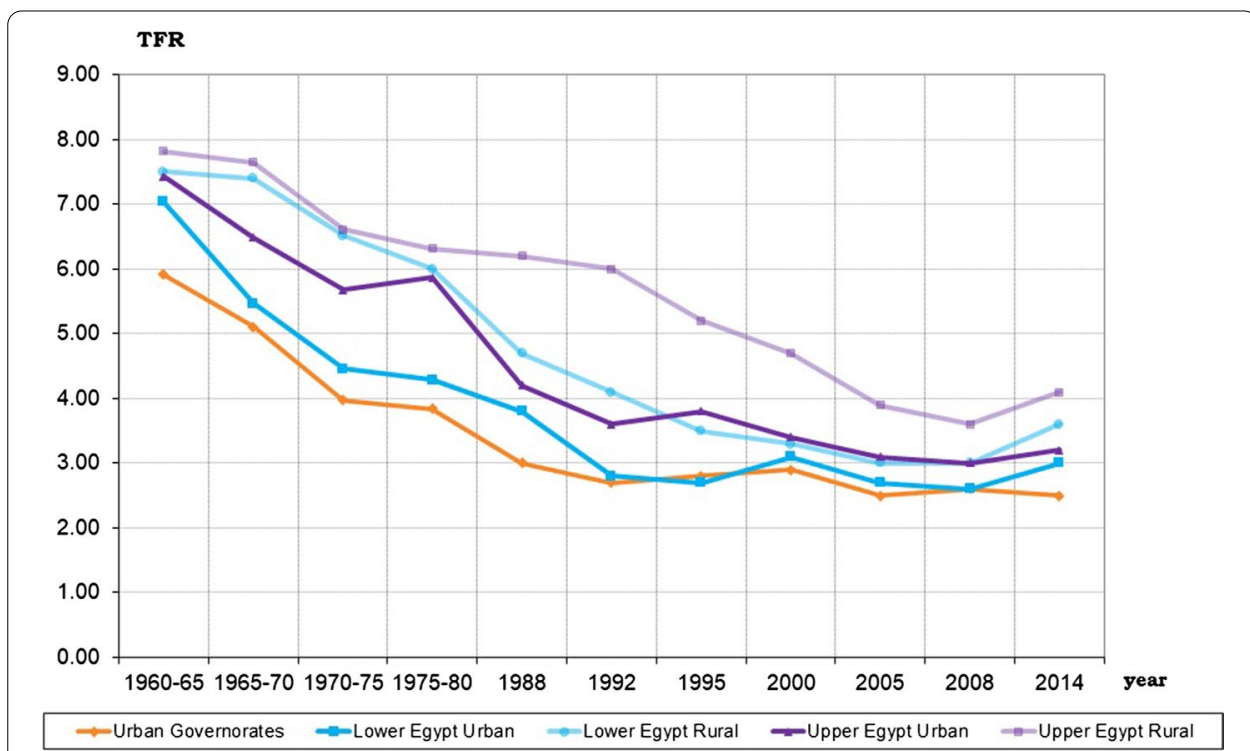

Fig. 2 TFR trends in Egypt by governorates 1960-2014. Sources: DHS (various years for the data from 1988 to 2014) and EFS for the data from 1960 to 1980

geographical and social context (including space variables) and using spatial analysis framework, such as geographical weighted regression, spatial fixed effect panel model, spatial Durbin model.

\section{Fertility decline in Egypt: a look at the geographical dimension}

The main sources of data to analyse fertility transition in Egypt are the Demographic and Health Surveys (DHS). From 1988 onward, 7 surveys (1988, 1992, 1995, 2000, 2005, 2008 and 2014) and 2 ad interim surveys (1998 and 2003) were carried out. For the 2 decades preceding the surveys, data from Egyptian Fertility Surveys (EFS) provide estimations of fertility rates. While survey data are useful to study fertility determinants, they only provide reliable estimations of the main demographic indicators at the regional level. Thus, they are not useful for analysis of the spatial evolution of fertility at a detailed level. However, we provide a descriptive analysis of fertility trends from 1960 to the present day using survey data because the spatial differences are also significant at the macro level. $^{2}$

The evolution of TFR at the regional level is presented in Fig. 2 for the period 19602014: we observe a twofold separation at the beginning of the period, first between towns and countryside and then between Lower (Nile delta) and Upper Egypt (Nile valley). In the 1960s fertility was particularly high in Upper Egypt (both rural and urban) and in rural areas of Lower Egypt. Between 1960 and 1975 fertility declined quite rapidly in the urban areas. The fertility decline affected rural areas at different rates. For instance, the decline in rural Upper Egypt was the last to take place in the second half of the 1990s, while in Lower Egypt it started twenty years earlier. In the period 1988-2000

\footnotetext{
${ }^{2}$ From the administrative point of view, Egypt is divided into 27 Governorates, which are usually grouped in 5 major regions: Urban Governorates, Lower Egypt urban, Lower Egypt rural, Upper Egypt urban, and Upper Egypt rural (we exclude the Frontier Governorates as very sparsely populated).
} 
fertility levels remained almost stable in urban areas, particularly in urban Governorates and in the cities of the delta region. The decline continued in the rural areas until the beginning of the twenty-first century. In the early years of the new millennium, fertility plateaued at around 3 children per woman in Egypt. Then it rose to 3.5 children per women between 2008 and 2014. During the last decade, fertility fell in the urban Governorates while it rose in the rural ones and in the cities of the Nile delta. For example, the TFR in rural Upper Egypt reached 4.1 children per woman in 2014 as compared with 3.6 in 2008, while in the same period it decreased from 2.6 to 2.5 in Urban Governorates.

Fertility patterns at the spatial level are important in the Egyptian context as they may shed light on past and future trends and help to formulate policies to lower fertility levels. However, there are very few studies that have addressed the fertility transition in Egypt at the spatial level. Denis and Moriconi-Ebrard (1998) analysed the evolution of the Egyptian population at the regional level, using census data from 1897 to 1996 . They provided a classification in 6 Egyptian regions according to the different rate of population growth of each region. Their findings show that Cairo and Alexandria behave differently from the other regions: with a marked population increase up to the 1970s, the area surrounding Cairo proved the most dynamic as from the 1970s; Middle Egypt followed the same pattern notwithstanding the high emigration rate, and fertility was still high in this region. There was also a remarkable increase in the population of the neighbouring areas and of the New Cities, largely promoted by the Government and sponsored by the international donors as an alternative to the crowded areas of Cairo and of the delta. Conversely, the population had greatly increased in the region of the delta.

Three studies were carried out by Weeks et al., $(2000,2004,2010)$ on the spatial dimension of fertility. In the first study fertility variations are addressed in one of the most densely populated areas in Egypt, the Governorate of Menoufia, between 1976 and 1986. The findings show significant fertility variations within rural areas, due to where the villages are located within the region and human capital factors (female education). The second study addresses fertility variation in the Greater Cairo urban area between 1986 and 1996. Weeks et al. found a great variation in fertility within the area: fertility is lower in the areas of the city centre, while it is higher in the suburbs. The differences in fertility are mainly explained by differences in human capital, and especially women's education. The third study integrates the previous study on the Governorate of Menoufia by investigating changes occurred between 1976 and 1996. Results confirm a relevant spatial variability in 1976 and 1986 and show that fertility decline occurred in the governorate between 1986 and 1996 took place in areas where illiteracy drop. Findings indicate that spatial patterns are influenced by fertility of neighbourhood villages rather than a similarity between the villages. A fourth study was carried out in 2006 by Bonneuil and Dassouki: they reconstructed TFR in the period 1960-1996 for 4905 administrative subdivisions in Egypt using census and population register data, showing the huge heterogeneity of fertility within Muhafaza. Additionally, they found that all other things being equal, there is a strong spatial gradient in fertility measured by the distance to Cairo, together with an effect of the nearest neighbours and of the main city of the Muhafaza.

While the fertility transition in Egypt has been researched in depth thanks to DHS data, the spatial diffusion of fertility has remained largely unexplored: there is no map available to study the geography of fertility on a fine scale over a long period of time. In 
fact, lacking these supports we have no knowledge of the elementary characteristics of the spatial pattern of fertility decline in Egypt. Our study tries to fill this important gap in the picture of fertility trends in the Egyptian context. We will try to answer the following research questions: (RQ1) Has there been a spatial diffusion of fertility control? (RQ2) Where and when did the fertility decline began? In which territories did it spread first/last? (RQ3) Through what mechanisms did the spatial diffusion occur?

We formulate three main hypotheses. First, (H1) we assume the fertility decline diffused spatially in Egypt. In fact, many studies have already shown this pattern in other countries. Second, (H2) we assume the fertility decline began in Cairo and then spread to the Nile delta, and lastly to the Nile valley. Finally, (H3) we assume that spatial diffusion occurs through two traditional mechanisms: contagion diffusion (by geographic proximity) and hierarchical diffusion (Saint-Julien, 2007).

\section{Materials and methods}

In this section, we present the data and methods used for our study. First, we justify our choice to use census data to estimate fertility. Then, we present the indirect method of fertility estimation, namely the child-woman ratio (CWR), as well as the mapping methods used. The geographical dimension of our approach requires the use of basemaps, which had to be created in part to match the demographic data used. Finally, we present the mapping approach, and the spatial statistics methods used.

\section{Census data}

To describe how fertility has declined in space, the ideal is to use a sub-national level of a certain geographical completeness. If the level of observation is too aggregated, such as at the national level, it will be difficult to describe spatial processes accurately, in particular in the case of spatial diffusion. The challenge is to find demographic data that meet this requirement.

In this context, survey data are not an adequate data source. Indeed, they are often representative at the national level, sometimes at a highly aggregated regional level (e.g. DHS surveys), but never at a detailed sub-national level. Surveys are generally not designed to observe spatial processes, and are even less likely to show close detail, because this would require a significant increase in the sample size and therefore in the survey budget.

Indeed, the appropriate data sources for our study are the sources tending towards exhaustiveness, namely the population census and civil registers. These traditional sources in demography make it possible to work on a detailed geographical scale because, compared to surveys, the problem of statistical representativeness is much less acute. From this point of view, "Egypt has a long tradition of registering civil status and counting the population. Registration is very close to exhaustiveness and the population is sufficiently concentrated to facilitate censuses" ${ }^{\prime 3}$ (Courbage, 1994, p. 1045). The data of the population censuses in Egypt are characterized by their reliability (Fargues, 2002).

For this study, we had access to a part of the database distributed by the CEDEJ. ${ }^{4}$ It is a geocoded and geo-referenced database of census population data from 1882 to 2006.

3 Translated by the authors from French: "l'Egypte jouit d'une longue tradition d'enregistrement des faits d'état civil et de dénombrement de la population. L'enregistrement y est très proche de l'exhaustivité et la population est suffisamment concentrée pour faciliter les recensement".

4 @CEDEJ-CAPMAS / @Hala Bayoumi (dir.)- 2018. 
Table 1 Number and average population of qism/markaz levels (1960-2006)

\begin{tabular}{lrrrrr}
\hline & \multicolumn{1}{c}{$\mathbf{1 9 6 0}$} & $\mathbf{1 9 7 6}$ & $\mathbf{1 9 8 6}$ & $\mathbf{1 9 9 6}$ & $\mathbf{2 0 0 6}$ \\
\hline Qism & & & & & \\
Number & 85 & 102 & 121 & 140 & 172 \\
Average population & 90,181 & 135,044 & 136,279 & 152,673 & 156,519 \\
Markaz & & & & & 162 \\
Number & 116 & 131 & 158 & 162 & 289,508 \\
Average population & 155,760 & 181,670 & 197,879 & 239,878 & 334 \\
Total & & & & & 302 \\
Number & 201 & 233 & 279 & 199,607 & 222,403 \\
Average population & 128,028 & 161,147 & 171,289 & &
\end{tabular}

Source: OCEDEJ-CAPMAS/@Hala Bayoumi (dir.)- 2018

Within this framework, we have the population structure by 5 -year age group and sex at the qism/markaz ${ }^{5}$ level for five population censuses between 1960 and $2006 .{ }^{6}$ This administrative level is ideal for our study since it distinguishes between predominantly rural territorial units (markaz) and urban units (qism), unlike governorates, which often aggregate these two types of spaces within the same territorial unit (with the exception of urban governorates). Thus, it is possible to directly test our hypothesis on the spread of fertility decline from cities to the countryside.

Like most administrative levels, the qism/markaz level undergoes changes over time. The number of administrative units is not stable (see Table 1). Indeed, it increased from about 200 in 1960 to almost 350 in 2006. An interesting trend to note is that the number of rural territories (markaz) has remained stable since 1986 and even fell below urban territories (qism) in 2006. Regarding the population evolution, the increase in the average population between 1960 and 2006 was equal to $73.6 \%$ in the qism and $85.9 \%$ in the markaz.

\section{Methods for indirect fertility estimation}

We do not have civil status data at the qism/markaz level for the entire study period. In fact, with census data alone we are compelled to use indirect fertility estimation methods, calculating a child-woman ratio ${ }^{7}$ (CWR). With this indicator it is possible, at each census, to estimate the fertility level of a sub-national territory, but also fertility trends over the entire period.

The objective of this article is to describe the decline in fertility from a geographical point of view. To do so, we chose to apply the method used by Guilmoto and Rajan (2001), whose data and research questions are very similar to ours. Thus, we calculate 2 different types of CWR. The first (CWR1) relates the number of children aged 0-4 years to the number of women aged 15-49 years. The second (CWR2) relates the number of children aged 5-9 years to the number of women aged 20-54 years. CWR1 estimates the fertility level for the 5 years preceding the census, while CWR2 estimates it for the

\footnotetext{
5 The qism/markaz is the 2nd administrative level in Egypt, lower than that of the governorates.

6 1960, 1976, 1986, 1996, 2006.

7 The child-woman ratio is the number of children aged 0 to 4 divided by the number of women aged 15 to 49 .
} 
Table 2 Descriptive statistics of CWRs at each period

\begin{tabular}{lcclllll}
\hline Period & Mean & Median & $\begin{array}{l}\text { Standard } \\
\text { deviation }\end{array}$ & 1st quartile & 3rd quartile & Min. & Max. \\
\hline $1950-1955$ & 1525.3 & 1506.4 & 198.0 & 1407.0 & 1653.7 & 726.9 & 2245.2 \\
$1955-1960$ & 1350.0 & 1368.8 & 192.0 & 1252.9 & 1452.7 & 609.2 & 1914.3 \\
$1966-1971$ & 1145.1 & 1212.5 & 233.4 & 989.9 & 1304.9 & 468.9 & 1680.2 \\
$1971-1976$ & 1033.4 & 1084.3 & 251.1 & 849.6 & 1203.3 & 354.2 & 1523.9 \\
$1976-1981$ & 1130.4 & 1147.7 & 294.3 & 940.0 & 1342.4 & 372.5 & 1747.1 \\
$1981-1986$ & 1110.1 & 1113.0 & 330.3 & 897.4 & 1370.7 & 326.1 & 1791.7 \\
$1986-1991$ & 1013.7 & 996.9 & 312.7 & 784.4 & 1224.5 & 267.9 & 1651.2 \\
$1991-1996$ & 755.6 & 715.0 & 255.7 & 584.2 & 914.2 & 245.4 & 1348.1 \\
$1996-2001$ & 705.9 & 680.4 & 195.2 & 588.9 & 832.0 & 209.8 & 1600.3 \\
$2001-2006$ & 607.1 & 612.1 & 161.6 & 518.0 & 719.1 & 169.4 & 1188.3 \\
\hline
\end{tabular}

period between 5 and 10 years before the census. For example, for the 2006 census, CWR1 is a fertility indicator between 2001 and 2006, and CWR2 is a fertility indicator between 1996 and 2001. As we have 5 censuses at our disposal (from 1960 to 2006), with this method we are able to study fertility trends between 1950 and 2006, i.e. over more than 50 years.

However, the CWR has a significant flaw. It is measured with children enumerated on the census date, i.e. surviving children. This indicator therefore excludes children who died before the population census. It is necessary to adjust the CWR for infant and child mortality, multiplying it by the appropriate ${ }^{8}$ survival ratio. ${ }^{9}$ The UN standard mortality tables provide a correspondence between these survival rates and the infant mortality rate (IMR) of a population. We make extensive use of this correspondence since the infant mortality rate is commonly estimated at subnational levels (governorates or large regions) by demographic surveys and statistical offices. Indeed, this indicator is widely available at regional levels. This avoids applying the national survival rate to all subnational territories. For the period 1950-1976, we use the infant mortality rates published by the Committee on Population and Demography of the National Research Council (1982), and those measured by DHS surveys conducted between 1988 and 2008 for the period after 1976. Thus, we collect IMRs by governorate (or large Egyptian region) and by type of environment (urban or rural). On the basis of correspondence, we deduce from this the survival rates we apply to the CWRs of qism/markaz on each census date in order to correct them by infant and child mortality. Finally, we standardize CWRs by the average CWR of all territories for all dates combined. The descriptive statistics of CWR at each period are summarized in Table 2 .

The CWR trends are consistent with the literature. The decline in fertility is visible through the decrease in the average CWR from 1525 in 1950-1955 to just over 600 in 2001-2006; likewise the increase in fertility in the mid-1970s is evident from the CWR increase in that period. On the other hand, the evolution of the statistical dispersion (standard deviation) is interesting: it increases from the end of the 1950s until

\footnotetext{
${ }_{5} \mathrm{~S}_{0}$ for CWR1 and ${ }_{5} \mathrm{~S}_{5}$ for CWR2.

9 The survival rate $\left({ }_{n} S_{x}\right)$ is a parameter of the mortality tables. It describes the probability of an individual surviving from age $x$ to age $x+n$.
} 
1981-1986, and then decreases continuously. This means that the values are more similar at the two ends of our study period (1950s and 2000s), and less similar in the intermediate periods (1970s-1980s). This finding implies that the fertility decline did not begin simultaneously in all territories. First, the fertility of some areas declined, which increased statistical dispersion. Second, the dispersion decreased when the fertility decline began in a large part of the territories. These results point to a process of diffusion, with territories that are both precursors and laggards. The challenge now is to determine how this diffusion is spatially organized.

\section{The basemaps}

In addition to census data, part of our work focused on the basemaps in order to map the fertility indicators obtained. To map fertility indicators, we need to choose a basemap carefully. Each census has a corresponding basemap, with as many polygons as territories considered in the census. Since the number of qism/markaz is not stable over time, the basemap differs from one census to another. Faced with this situation, we may choose whether or not to harmonize the basemaps. ${ }^{10}$ The purpose of this article is descriptive, so we do not opt for the harmonization of the basemaps for several reasons. First of all, it would mean in our case a significant loss of information from our database. Indeed, between 1960 and 2006, the qism/markaz level was essentially divided into administrative units, i.e. a territory subdivided into several territories. As we do not have the locality level, it is not possible to harmonize the censuses to the 2006 basemap. The 1960 census is therefore the only one that can serve as reference for harmonization. However, it is the census with the fewest territories (40\% less than the 2006 census). Our study would lose in fine detail over the entire period.

In addition, our hypotheses focus on a comparison of urban and rural areas. The administrative changes of qism/markaz since 1960 mainly concern urban territories. Such is the case of rural areas that are urbanizing with rural exodus and urban sprawl, for example on the outskirts of large cities. These are also urban areas that combined with their countryside at date $t$ and obtained separate administrative status at date $t+n$. In this case, there is a markaz at $t$, then a markaz and a qism at $t+n$. Harmonization of data would hide an important part of the urban phenomena, including the emergence of new cities after 1960 .

Our aim is to describe the spatial pattern of fertility decline, and use of a different basemap for each census therefore raises no problems. In practice, we prefer the completeness of the data to their harmonization. Originally, we only had the 1996 and 2006 basemaps at our disposal. Based on the administrative changes of qism/markaz since 1960, we have reconstructed the basemaps of the 1960, 1976 and 1986 censuses. In addition, we have chosen not to include desert governorates in our study area. We focus only on the territories of the delta and the Nile valley, where more than $90 \%$ of the Egyptian

\footnotetext{
10 This operation consists in making the territorial grid constant over time, i.e. obtaining the same number of territories for each census. For this purpose, a census is chosen as a reference. By reconstructing the transformations at the administrative level (merger, division, etc.), the other censuses are modified so that the number of territories corresponds to that of the reference census. Thus, the harmonization of map backgrounds necessarily implies a harmonization of data The main advantage of this method is that it is easier to compare the different maps since they have the same basemap for all censuses.
} 


\section{Location map of the Nile Delta}

\section{Mediterranean}

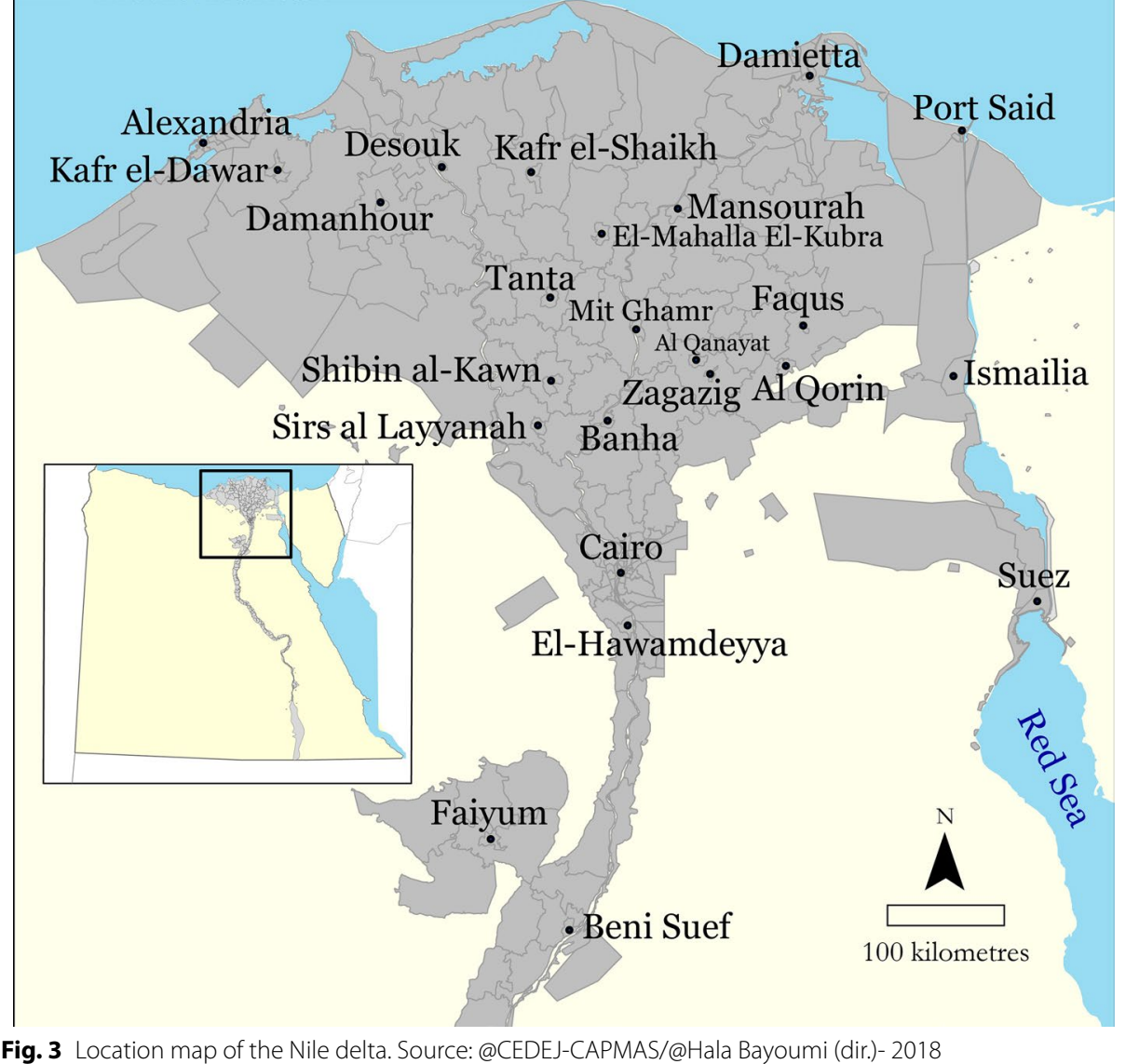

population are concentrated. Egypt extends over $1000 \mathrm{~km}$ from north to south and over a very small area in the Nile valley.

\section{Mapping and spatial statistics}

We calculated CWRs at the qism/markaz level for 10 periods (1950-1955 to 2001-2006) and mapped this indicator at each period. For this, we apply the same discretization for all the maps, so that the maps are comparable to each other. After analysing these maps, we identified some characteristics of the spatial pattern of fertility transition in Egypt. Each feature is illustrated by the most relevant maps, representing the whole of Egypt to prevent too many maps in the article. Because of the Egyptian spatial configuration, it is difficult to have both an overview and a detailed view from a map of Egypt as a whole. Thus, in order to have an overall view of the spatial diffusion between 1960 and 2006, we provide in appendices a panel of all the maps at the scale of Egypt (Annex 1), as well as a panel with the maps zoomed on the Nile delta (Annex 2) and another panel with the maps zoomed on the Nile valley (Annex 3). In addition, to facilitate reading of the maps, 


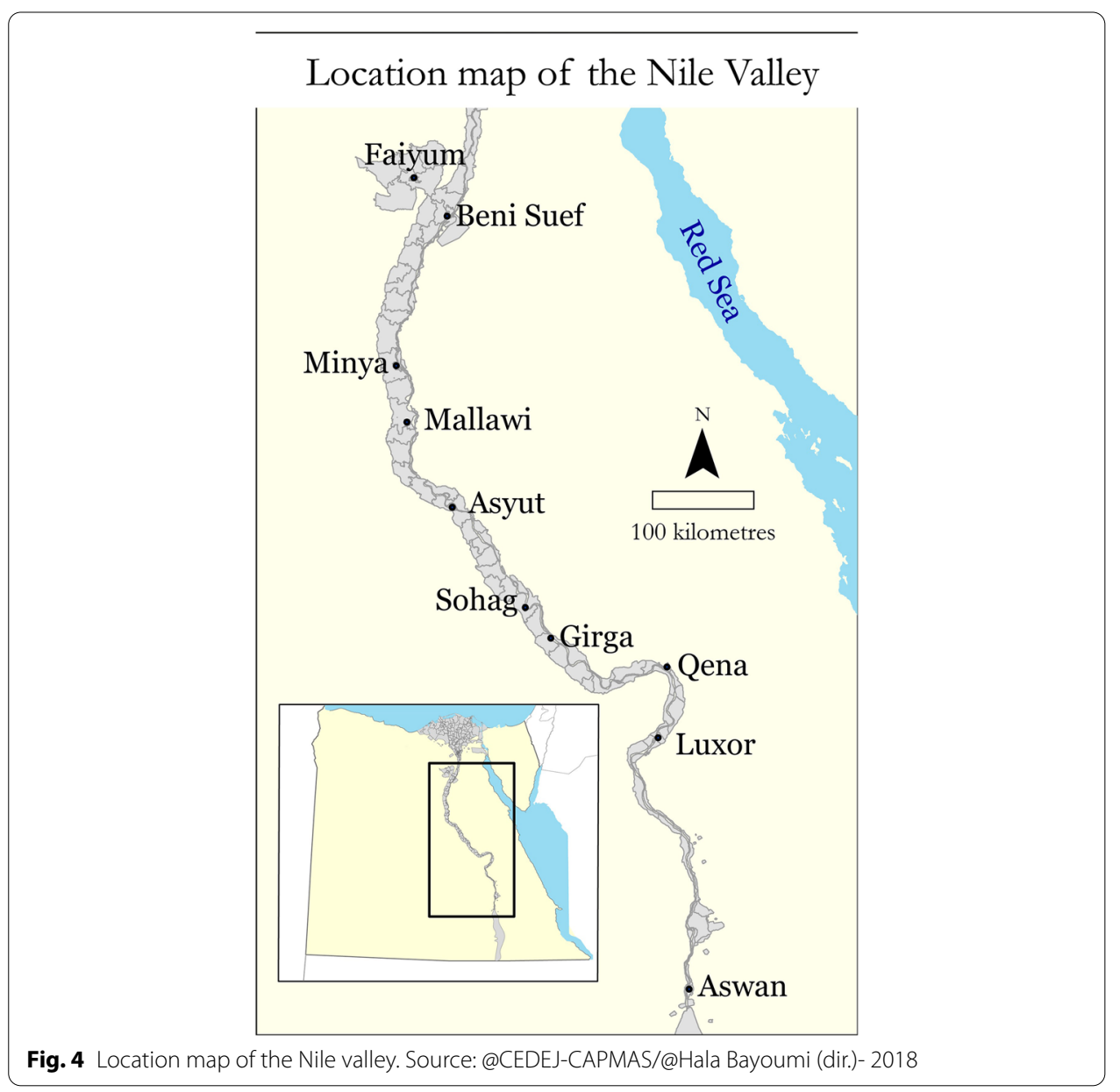

we have made two location maps with the cities used in the text of this article (see Figs. 3 and 4).

The maps highlight several geographical characteristics of the decline in fertility in Egypt. However, despite its great usefulness, this method has the disadvantage of relying on visual interpretation of the maps, which can be biased both by the reader and by the statistical discretization of the values (Costa, 2015; Guilmoto \& Rajan, 2001). For this reason, we analyse the evolution of the spatial structure of fertility in order to verify the findings and test the validity of our hypothesis. To do this, we measure the spatial autocorrelation of the data, that is to say whether the fertility value of a territory is dependent on the values observed in neighbouring territories. One of the most widely used indicators is Moran's I (Anselin, 1988), which can be interpreted as a correlation coefficient: 1 means a perfect positive spatial correlation, i.e. the fertility level of a territory is positively correlated with that of neighbouring territories; -1 means conversely a perfect negative spatial correlation; and 0 means an absence of correlation between the level of a territory and that of its neighbours. The inverted U-shape of the evolution of spatial autocorrelation over time can be interpreted as a sign of spatial diffusion (Costa, 2015). When the birth control emerges in the precursor territories, the phenomenon is spatially structured and spatial disparities are increasing: 
some areas still have high fertility while others have lower fertility. In this case, spatial autocorrelation increases as long as the decline in fertility only concerns part of the country's territories (Guilmoto \& Rajan, 2001). In a second stage, the fertility transition affects all the territories, which leads to a spatial homogenization of fertility and less spatial disparities: spatial autocorrelation decreases (Vitali et al., 2015).

To calculate Moran's I, it is necessary to choose a spatial weights matrix (W) among several possible criteria (contiguity, distance band, K-Nearest neighbors...). The spatial configuration of Egypt is particular: the vast Nile delta contrasts with the narrow Nile valley. This is in addition to the heterogeneity of the qism/markaz level in terms of surface area, and to the fact that some territories are not contiguous with other territories (while sometimes being close). In fact, if we choose the contiguity criterion, the scale considered by the neighborhood can vary significantly for the same contiguity order and some territories will be without neighbors. For these reasons, we choose the criterion of the distance band, which, in addition to being more to the spatial configuration of Egypt, is an interesting intuitive spatial notion. We represent the evolution of Moran's I between 1950 and 2006 for different distances (from 25 to $100 \mathrm{~km}$, in $25 \mathrm{~km}$ increments) to analyse the sensitivity of the results.

Moran's I measures the global spatial autocorrelation of the data. However, as we aim to identify potential spatial regimes (local concentrations of similar values; Nile delta vs. Nile valley for example) and outliers (territories whose value is dissimilar to that of its neighbors), we use two methods in addition to Moran's I: the Moran Scatterplot and the Local Indicators of Spatial Association (LISA).

The first one allows to classify the spatial autocorrelation and identify different patterns of spatial association. It contains a series of points representing the standardized values of the territories according to those of the neighboring territories (Anselin, 1996). This graph allows us to identify 4 types of local spatial autocorrelation:

'High-high' (HH): territories with high fertility whose neighbouring territories have high fertility;

'Low-low' (LL): territories with low fertility whose neighbouring territories have low fertility;

'High-low' (HL): territories with high fertility whose neighbouring territories have low fertility;

'Low-high'(LH): territories with low fertility whose neighbouring territories have high fertility.

$\mathrm{HH}$ and LL are cases of positive spatial autocorrelation (the territory is similar to its neighbors), i.e. hotspot and coldspot. HL and LH are cases of negative spatial autocorrelation (the territory is different to its neighbors), and thus spatial heterogeneity (spatial outliers).

The second method (LISA) enables a more precise detection of the spatial structure of possible clusters and outliers, which are represented in specific maps. In addition, this method tests the significance of local spatial autocorrelation indices (Anselin, 1995). In fact, in addition to the 4 previous types (HH, LL, HL, LH), a new type is added: 'Nonsignificant' (territories with values close to the mean whose neighboring territories 


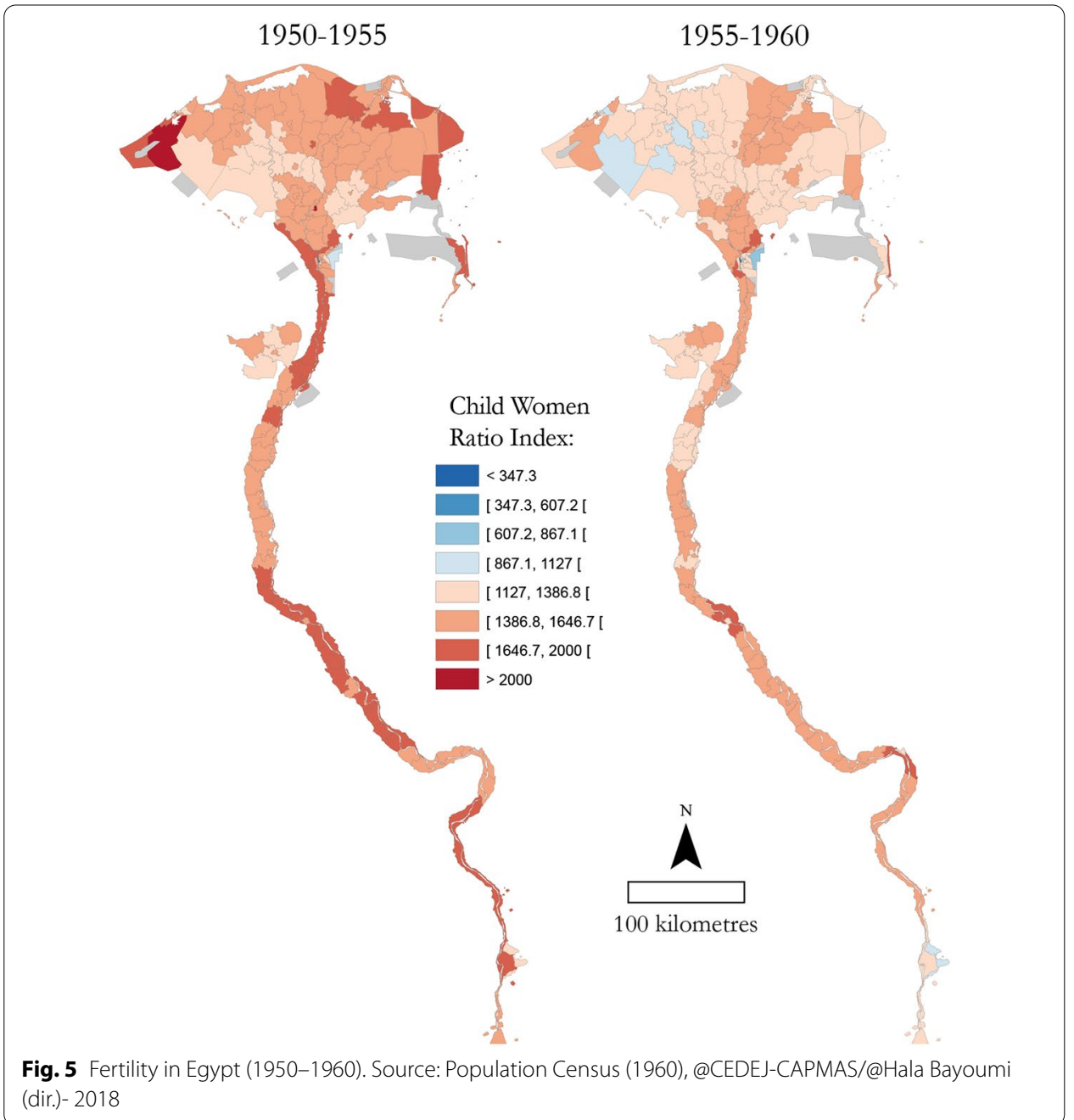

have values close to the mean). Finally, each territory belongs to one of these five categories, and by mapping them, we can very clearly identify the clusters of high fertility (hotspots), low fertility (coldspots), and spatial outliers. This mapping of local spatial autocorrelation allows us to objectify the spatial structure of fertility in Egypt, and to go beyond the visual interpretation of classical maps.

\section{Results}

Places where fertility control appears

The literature often shows that the decline in Egyptian fertility transition began in the early 1960s and earlier in the city of Cairo. With the data at our disposal, we can analyse fertility trends during the 1950s. Such analysis is rarely performed in Egypt for this period in studies at a sub-national level of analysis. In this way, we identify the regions that are precursors to the transition of fertility, while adding new insight to the current literature (see Fig. 5).

The fertility transition began well before the 1960s. The major cities were the precursors: the process was already underway in Cairo and Alexandria city centre in 


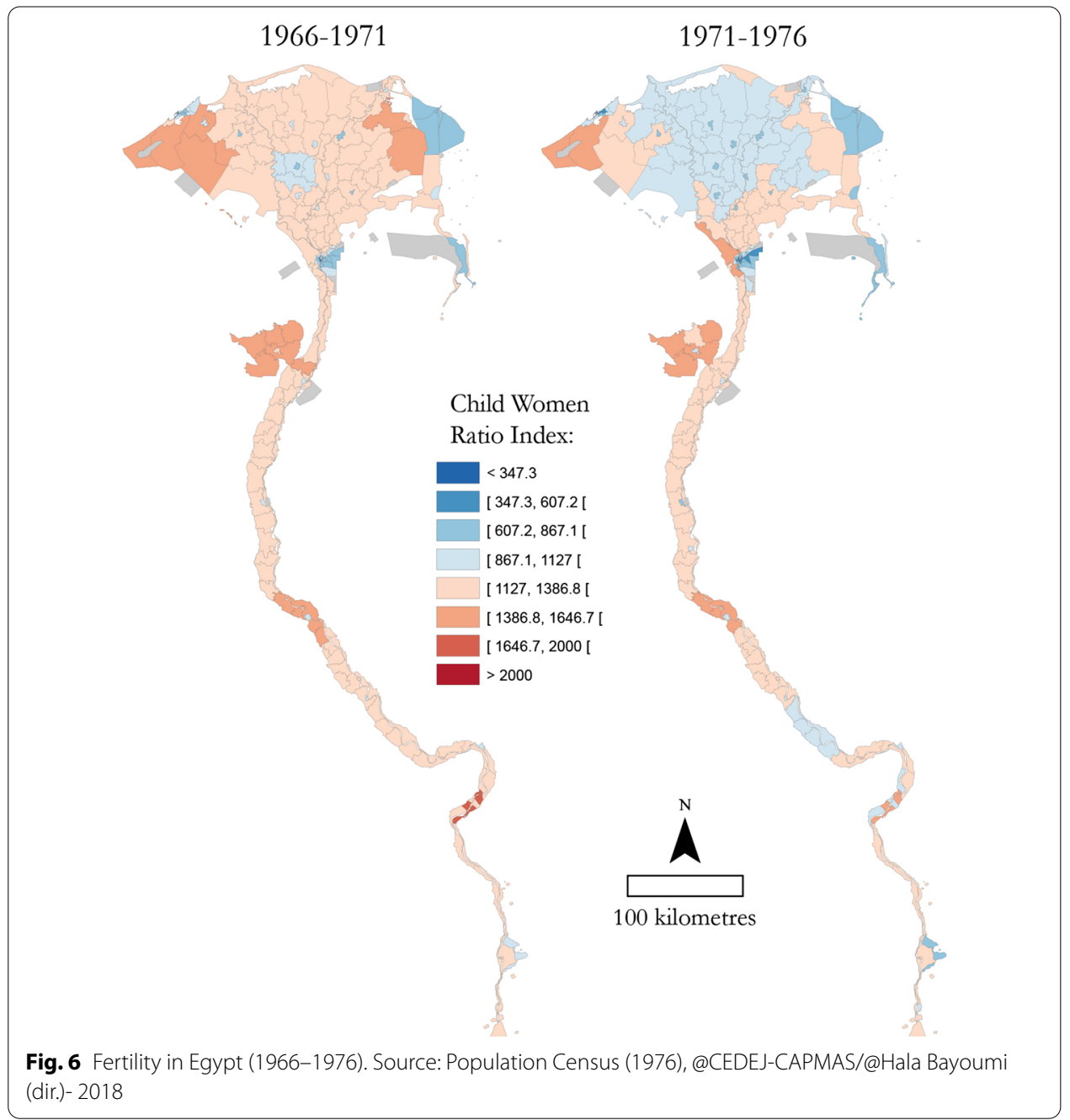

1950-1955, and in Port Saïd in 1955-1960. These three cities already had lower fertility levels (CWR below 867) than those reached by some regions in the 2000s. Other cities were also affected in the 1950s, but showed higher fertility than the three cities mentioned above. The precursor position of these cities could be explained by the fact that they had some of the highest levels of female literacy in Egypt in 1960.

In addition, in the 1950s, some rural areas had intermediate levels of fertility, including the Nile delta (west of the delta and around Zagazig), the Faiyum oasis, and the Beni Mazar and Aswan regions. This situation could mark the beginning of the fertility transition, although the point needs careful consideration. Demographers have shown that pre-transitional demographic regimes have a wide diversity of fertility levels, particularly in Europe (Chesnais, 1992). Thus, the intermediate fertility rates of these Egyptian rural regions may not be a sign of an early transition, but of lower pre-transitional fertility than in other rural areas.

Some of the rural areas identified above show a fluctuation in fertility between 1950 and 1971 (see Figs. 5 and 6), a recognized feature of pre-transitional demographic 
regimes. We can observe these trends for the regions on the western borders of the Nile delta or in Faiyum. Underestimation of the fertility indicator for these regions may account for these apparently erratic trends, due in part to under-reporting of children in the 1960 census. For these regions, it is difficult to conclude that there is an early transition in fertility.

However, these fertility fluctuations are not observed for rural areas in the central part of the delta (around Zagazig and Tanta), in the Beni Mazar and Aswan regions. These regions form contiguous clusters of intermediate fertility straddling several governorates. The clusters extended geographically to the rest of the Nile delta in 1955-1960, narrowing down very high fertility clusters in the north-eastern delta. It seems unlikely that estimation errors could be responsible for such data structuring, both in space (geographical clusters) and in time (spatial diffusion by geographic proximity). These factors argue in favour of an early transition to fertility in these rural areas.

The second characteristic of the spatial pattern of fertility decline in Egypt is the presence of areas of resistance to demographic change, where the fertility decline arrived late (see Fig. 5).

First, we distinguish resistant regions throughout the 1950s, the northeast delta (markaz surrounding Mansourah), the area from Banha to Bani Suwayf (excluding Cairo), and the central part of the Nile valley. They constituted geographical clusters of high fertility throughout the 1950s, while the rest of the delta gradually reached intermediate fertility levels. The 1960s saw these clusters disappearing.

The eastern and western borders of the Nile delta, which are less populated and less urbanized, can be seen as lagging regions since their fertility was systematically higher than in the centre of the delta from the late 1960s onwards.

On the other hand, two areas proved more resistant over time: the Faiyum oasis and the rural region of Asyut. They maintained high fertility levels uninterruptedly until the late 1980s, despite intermediate fertility for Fayum in the 1950s.

\section{Uneven fertility increase during the 1970s and 1980s}

A striking feature of the Egyptian transition is a 10-year period from the mid-1970s showing a standstill in the fertility trend. Some demographers have even demonstrated that it was actually an increase and not stagnation that occurred (Ambrosetti, 2011; Bonneuil \& Dassouki, 2006; Fargues, 2003). These researchers interpreted this phenomenon as a response to improved household economic conditions due to the economic opening of the country in the Sadat period, and as the result of a return to religion in Egyptian society (where the sharia became one of the main sources of law) after the Nasser period, when it had been relegated to the background (Pagès-El Karoui, 2012). While studied at the national level, this period of fertility increase has been very poorly documented at the sub-national level.

This increase in fertility can be seen from the 1976-1981 (see Fig. 7) but it does not happen everywhere. The regions concerned were mainly rural, the most part of Egypt remaining unaffected, or at the most with far more limited increase. In the Nile delta, the fertility increase was limited to the western half of the delta and its eastern border, but also to some cities (El Mahalla El Koubra, Mit Ghamr, Banha, Al-Ismaliyya). On the other hand, this trend was more widespread in the Nile valley, from south 


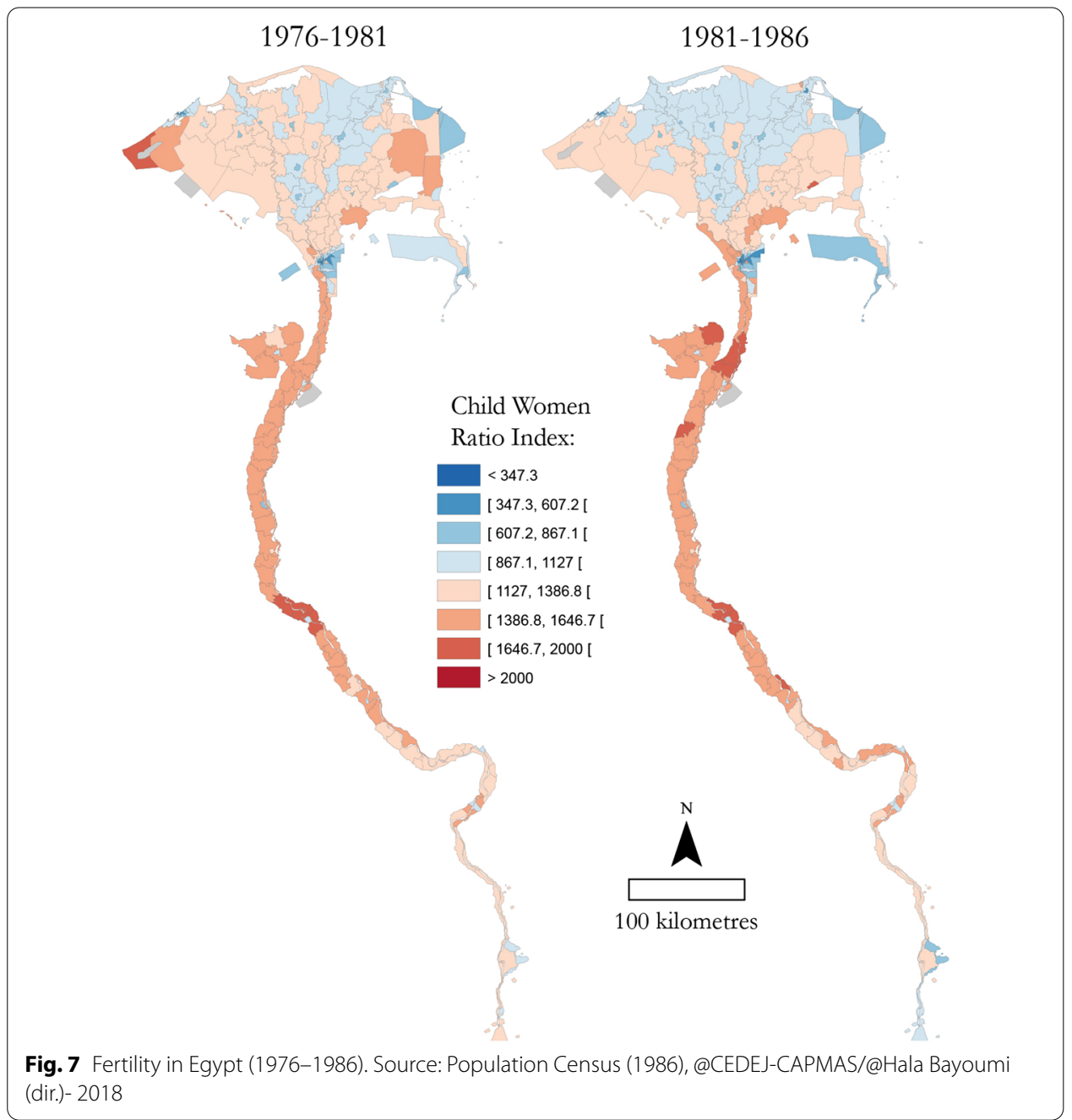

Cairo to Girga: many more regions were affected than in the Nile delta and the rural region of Asyut went on recovering very high levels of fertility. It should be noted that, with the exception of Mallawi, in this period fertility was not increasing in the cities of Upper Egypt or the southern part of the Nile valley (from Luxor to Aswan). Thus, great disparities were emerging between the cities of Upper Egypt and their surrounding countryside.

In 1981-1986, the fertility decline resumed in the Nile delta through spatial diffusion from cities to the countryside, particularly in the western part. The period of fertility increase did not last long in the delta, but it was not until 1986-1991, more than 15 years later, that the same levels of fertility registered in 1971-1976 were recorded.

While the increase in fertility ended in 1981-1986 in the Nile delta, this was not the case in Upper Egypt, where the geography of fertility remained the same until 1991 (see Fig. 8). In 1991-1996, fertility decline finally resumed throughout the Nile valley taking place through the contagion diffusion mechanism between qism and markaz, particularly in rural areas in the vicinity of the following cities: al-Fayyum, Bani Suwayf, al-Minya, Qina, Luxor and Aswan. Despite this general trend in the Nile valley, some local changes are worth highlighting. Some regions saw fertility increase with a delay in 


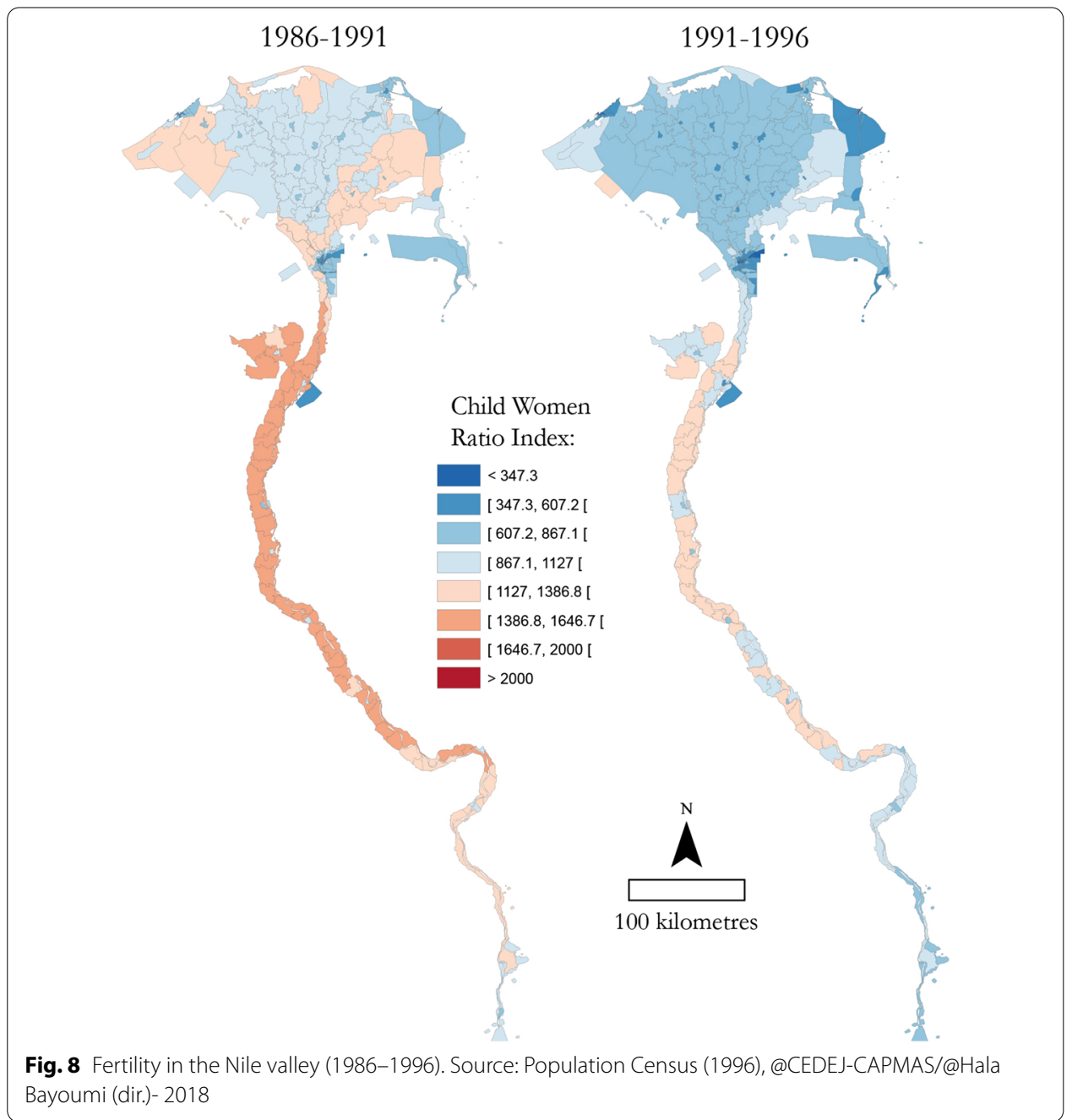

1981-1986 (north of Cairo, in the rural regions of Qina and Bani Suwayf), but also in 1986-1991 (region south of Suhag). From this period, the regions with very high fertility (rural regions of Asyut and Luxor, and north of Bani Suwayf) saw their level decrease. In addition, the Aswan region saw its fertility decline resume as early as 1981-1986, at the same time as in the Nile delta.

The analysis of the maps partially confirmed our initial hypothesis: in the Egyptian context the fertility decline diffused spatially (H1), however some patterns of this diffusion are unexpected (H2). For example, we found that some rural areas may have started the transition along with the cities. Then, it is interesting to verify differences between some areas and in which way the differences emerged.

\section{The origin of the contemporary contrast between delta and Nile valley}

The current fertility increase may lie behind the contrast between the delta and the Nile valley. For 20 years, between 1950 and 1971, the fertility transition took place in these Egyptian areas along classical lines. The precursor areas were located in the Nile delta, but fertility was also declining in the main cities of the Nile valley. From 1971 to 1976 
onwards, there was a spatial diffusion in the delta from cities to the countryside while the process did not take place in the Nile valley (with the exception of the Girga, Luxor and Aswan regions). It is as if the transition had stopped there and continued in the delta. This transition stall could have been be the premise for the resumption of fertility 5 years later, in 1976-1981. From this period onwards, we observe a generalized fertility increase in the rural areas of the Nile valley and more localized in the delta. In contrast, the fertility transition resumed much more rapidly in the delta (1981-1986) than in the Nile valley (1991-1996). The differences in the phasing of fertility transition between these two regions of Egypt are considerable: the Nile valley transition stopped 5 years earlier (1971-1976) and resumed 10 years later (1991-1996) than the delta transition. These elements partly explain the subsequent dichotomy between the valley and the Nile delta, which reached its peak in the late 1980s and early 1990s.

These results added some new elements to test our hypothesis (H2). Differently from expected, the fertility decline began in the same years in the Nile valley and the delta, and it was not until the early 1970s that most of the territories in the Nile valley experienced a fertility stall.

\section{Two spatial diffusion mechanisms: hierarchical and contiguous diffusion}

Two mechanisms are identified and show the existence of a spatial diffusion of fertility decline in Egypt: hierarchical diffusion and contagion diffusion (by geographic proximity).

The maps show how far Egypt's fertility transition is driven by cities (see Fig. 6). Urban populations are generally precursors, controlling their fertility earlier and to a greater extent than elsewhere. However, the transition did not begin at the same time in all the cities. To trace this differentiated timing, we focus on the order of cities reaching fertility levels in the 3rd value class (between 607 and 867). The first to be affected were Cairo in 1950-1955, Alexandria and Port-Said in 1955-1960, the three largest cities in the country. The next cities in order head the urban hierarchy: Tanta (certainly between 1960 and 1966), then Suez, Mansourah, Zagazig and Damanhûr in 1966-1971. The other qism of the delta, like al-Minya in the Nile valley, were affected in 1971-1976; and the rest of the secondary cities were affected thereafter. This timing is a sign of diffusion along the urban hierarchy of the country, where the fertility transition begins first in large cities, then spreads to intermediate cities and finally to smaller cities (Saint-Julien, 2007).

Our results highlight another process characteristic of spatial diffusion, namely the diffusion of fertility control by geographic proximity. For example, it is observed with the spatial extension of intermediate fertility clusters in the central delta between 1950 and 1971 (see Figs. 5 and 6), and between 1976 and 1996 with the spatial diffusion of lower fertility rates (see Figs. 7 and 8). This process is also observed with the spread from cities to their nearest rural areas. This type of distribution characterizes almost all the cities, but not at the same time. It occurred between 1950 and 1971 in the biggest Egyptian cities (Cairo, Alexandria, Port-Saïd and Tanta) where lower fertility rates spread from the central districts to the inner suburbs and surrounding areas during 1960s. This spread from cities to the rural peripheries occurred in other cities in the central delta in the early 1970 s and it was slower in the Nile valley, where the lower fertility levels achieved 


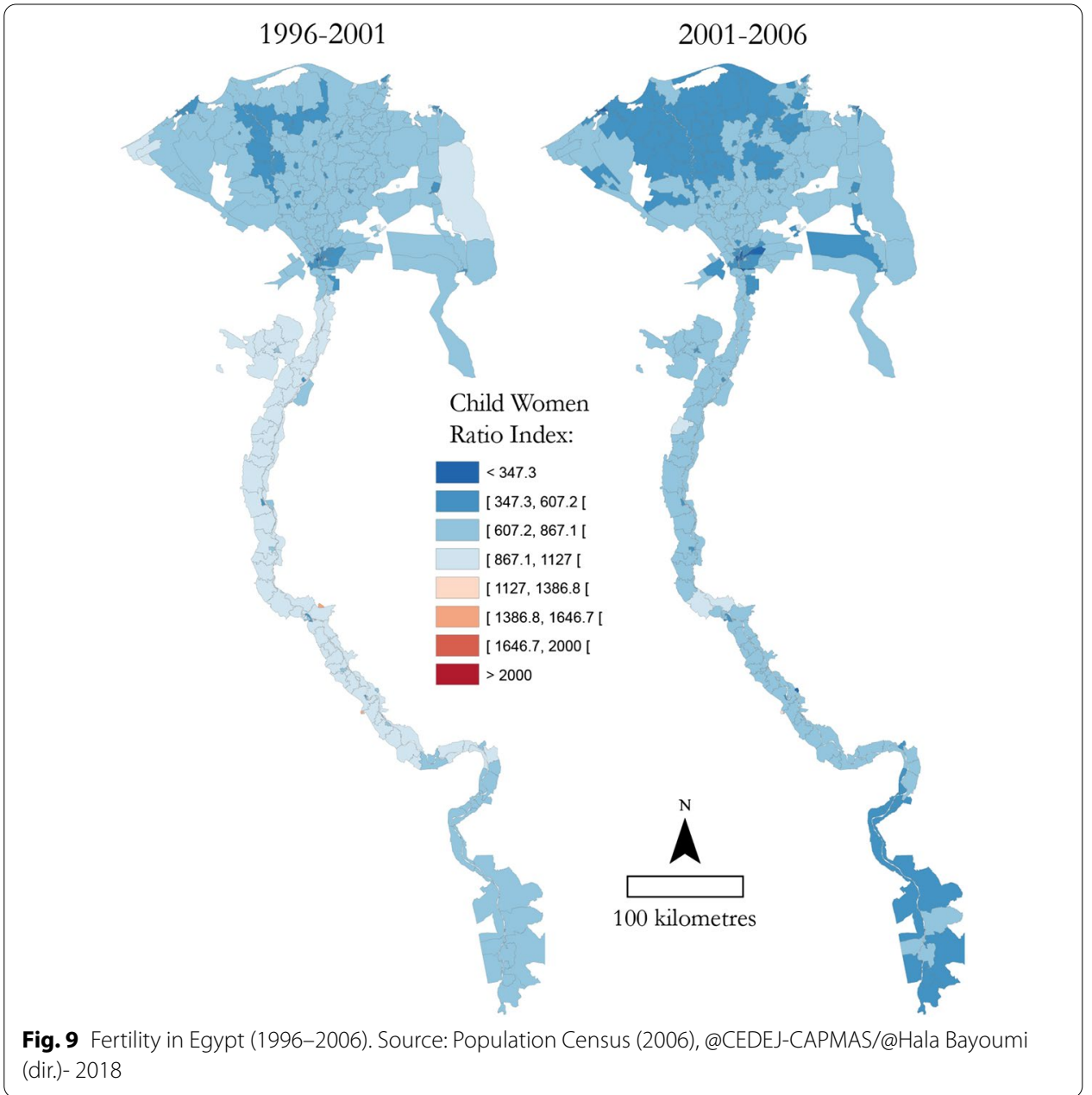

by cities did not extend to the surrounding countryside until the 1990s. This contagion distribution tallies with the findings of Bonneuil and Dassouki (2006), who measured a marked neighbourhood effect in the decline in fertility in Egypt.

It is interesting to note a specificity of Cairo with regard to this process of contagion diffusion. Despite their close proximity to the Egyptian capital, the regions in western Cairo maintained high fertility levels until the late 1980s. This spatial discontinuity between Cairo and its western suburbs had already been identified in the literature (Weeks et al., 2004).

In addition, recent fertility trends continue to be affected by this contagion diffusion. Maps from 1996 onwards show this phenomenon very well, with low fertility spreading to the north-western part of the Nile delta, and to the northern suburbs of Greater Cairo (see Fig. 9).

As hypothesized, the spatial diffusion of fertility decline in Egypt is characterized by two mechanisms of spatial diffusion (H3). Although the descriptive analysis provided results able to test our hypotheses, it is necessary to verify with analytical measures these descriptive findings. These further steps of the analysis will complete the results and will help to reply to our research questions. 


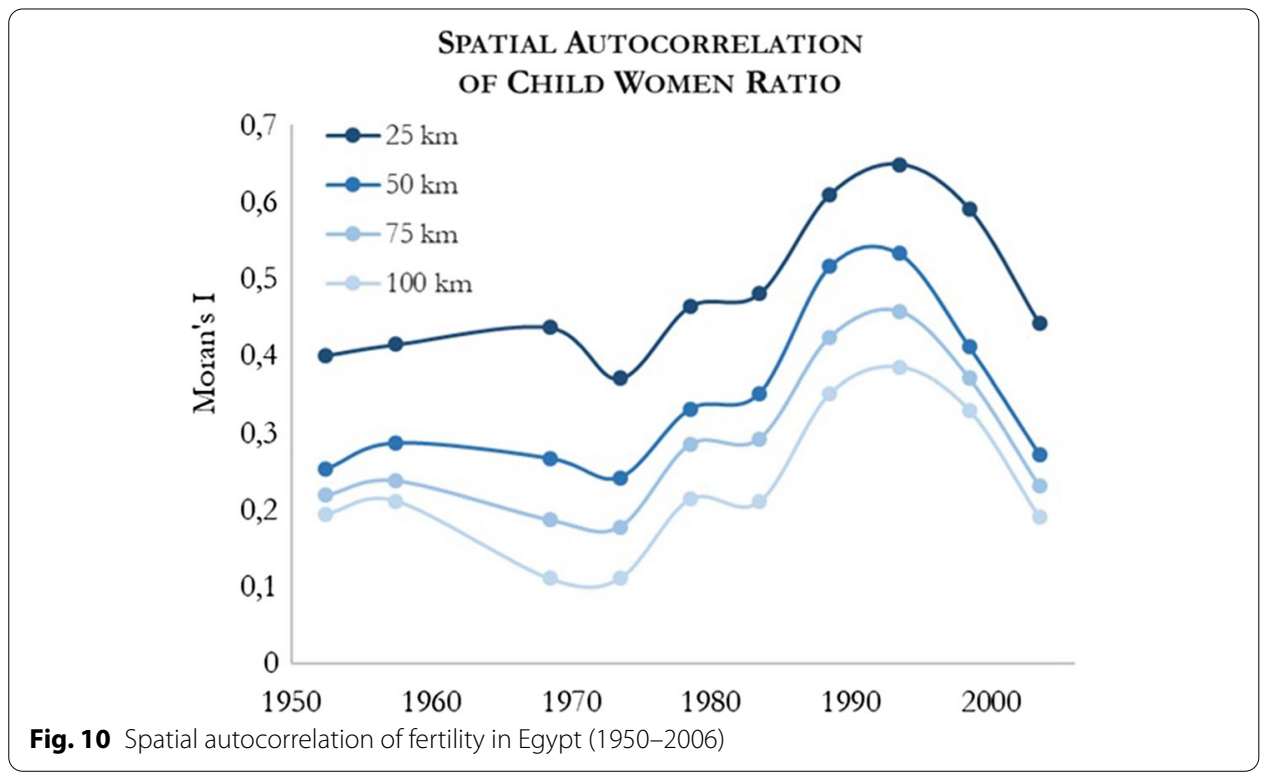

\section{Spatial diffusion and spatial autocorrelation}

We calculated the Moran's I for each period and for different neighborhoods: a distance ranging from 25 to $100 \mathrm{~km}$, in $25 \mathrm{~km}$ increments (see Fig. 10). Quite classically, the greater the distance, the lower the Moran's I: fertility is strongly structured at a local scale. Then, the evolution of Moran's I over time is broadly similar for all distances. Indeed, we find the inverted U-shape in 2 phases, which is a sign of spatial diffusion. However, the early period (1950-1971) shows different trends according to the spatial weight matrix. During this period, Moran's I increases only for a distance of $25 \mathrm{~km}$, while it decreases for other distances. This may mean that in the early stages of process, the contagion diffusion takes place in a very close neighborhood. After the period 1950-1971, the trend in the evolution of Moran's I is similar for all distances. In the following, we focus on the $25-\mathrm{km}$ spatial weights matrix, because we are interested in the local structuring of the phenomenon, and not in a regional structuring. The initial level of spatial autocorrelation is 0.4 , meaning that spatial disparities in fertility already existed in Egypt: either the fall in fertility began earlier than our observation period, or spatial disparities existed during the pre-transitional situation. Between 1950-1955 and 1966-1971, spatial autocorrelation increases. Indeed, this is the period when the spatial diffusion of the fertility decline starts, birth control appears in the large cities and then spreads to neighbouring territories. Then, spatial autocorrelation decreases in 1971-1976 when the decline in fertility starts to affect a greater number of territories, especially in the Nile delta and in some regions of the Nile valley. However, a further increase in spatial autocorrelation is observed from 1976-1981, reflecting the beginning of the fertility recovery in the Nile valley and parts of the delta. As the fertility transition resumes earlier in the Nile delta (1981-1986) than in the Nile valley (1991-1996), the heterogeneity between territories increases and the Moran I continues to increase. Spatial autocorrelation reaches a maximum of 0.65 in 1991-1996, when the fertility transition resumes in the Nile 


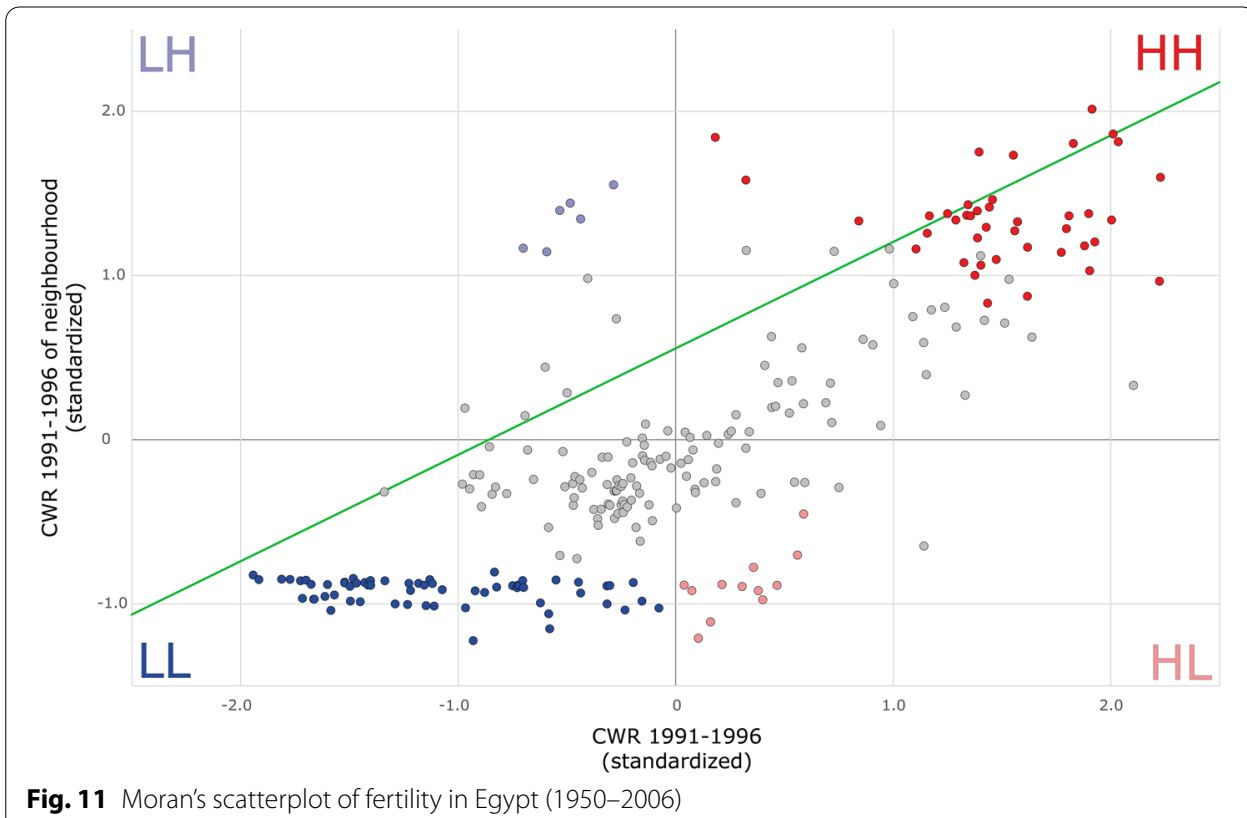

valley and the spatial disparities of fertility are the greatest in Egypt. The spatial autocorrelation decreases in the last periods, when the fertility resumes in all the territories and we observe a reduction of the spatial disparities. This does not mean that there is no longer a spatial structure of fertility in Egypt (Moran's I remains at 0.44 in 2001-2006), but that the local spatial structuring is less strong than before.

To identify spatial regimes of fertility and outliers, we use the Moran Scatterplot (see Fig. 11) and LISA mapping ${ }^{11}$ (see Fig. 12), only for the period 1991-1996, when local spatial structuring is strongest, and when the dichotomy between the Nile valley and the Nile delta has reached its peak. These two figures can be analysed simultaneously. For ease of comparison, we have colored the Moran Scatterplot points according to their category (HH, LL, HL, LH, non-significant). Both Moran Scatterplot and Lisa Map confirm the existence of spatial regimes. As descriptive results showed, a very clear opposition appeared between the Nile valley and the Nile delta, by analysing LISA map. Indeed, hotspots (clusters of $\mathrm{HH}$ ) are only in the Nile valley, mainly in the Faiyum area of Beni Suef, and in the central part of the valley (from Mallawi to Qena). In contrast, the Minya region, and the southern part of the valley (from Qena to Aswan) are non-significant, i.e. the fertility is close to the average. On the other hand, the coldspots (groupings of LL) are only in the Nile delta, and in particular in the large cities and their agglomerations (Cairo, Alexandria, Port Said). Using LISA mapping, we can identify spatial outliers, whose spatial distribution is particularly interesting. The HL territories are only in the Nile delta, close to Cairo and Alexandria. This highlights local spatial heterogeneity, with low fertility in the central part of the two large agglomerations and high fertility in the peripheries. This finding is consistent with the study of Weeks et al. (2004) on the greater Cairo area. It means

${ }^{11}$ LISAs were calculated with 99,999 permutations and a 95\% significance level. 


\section{Local Spatial Autocorrelation of FERTILITY IN EgYPT}

(1991-1996)

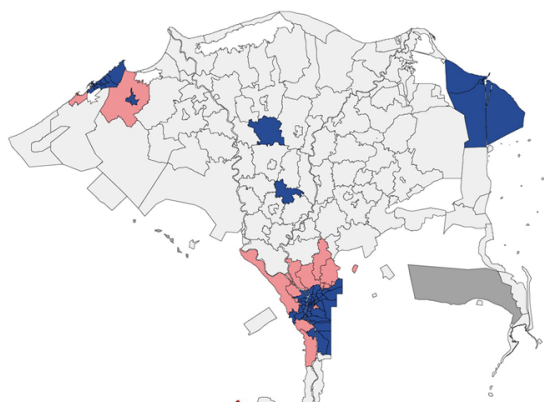

Local Spatial Autocorrelation: (25 kilometers neighborhood)

Positive: high fertility in a high fertility neighbourhood $(\mathrm{N}=44)$

Negative: high fertility in a low fertility neighbourhood $(\mathrm{N}=12)$

Positive: low fertility in a low fertility neighbourhood $(\mathrm{N}=62)$

Negative: low fertility in a high fertility neighbourhood $(\mathrm{N}=6)$

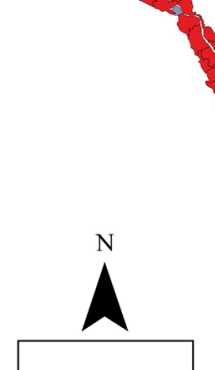

Not significant $(\mathrm{N}=128)$

Without neighbours

100 kilometres

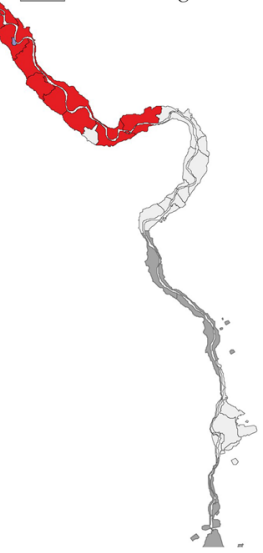

Fig. 12 Local Spatial Autocorrelation of Fertility in Egypt (1991-1996). Source: Population Census (1996), @ CEDEJ-CAPMAS/@Hala Bayoumi (dir.)- 2018

that on a national scale, even if these two large cities are forerunners in the fertility transition, there are still local spatial heterogeneities. In contrast, the LH territories are only cities in the Nile valley: Faiyum, Beni Suef, Minya, Asyut, and Sohag. Most of them are located within a high fertility hotspot. This confirms the particular behavior of cities, even in the Nile valley, which is the fertility hotspot in Egypt. This analysis show the existence of spatial regimes, therefore spatial non-stationarity. To model this phenomenon, we should use specific analytical methods, such as Geographically Weighted Regression (Brunsdon et al., 1996). An analysis such as this would allow 
more investigation of the spatial regimes observed here and connect this descriptive analysis to analysis conducted with more advanced spatial methods.

These measures of global and local spatial autocorrelation are in line with the findings emerged though the previous cartographic approach and, as the descriptive results, partially confirmed our initial hypothesis and contribute to draw our conclusion about the results and research questions we had set at the onset of our analysis.

\section{Discussion and conclusions}

With the aim of studying spatial patterns of fertility decline in Egypt (RQ1), its timing and territorial location (RQ2), and the mechanisms (RQ3), in our study we made specific hypothesis. We hypothesized a spatial diffusion of fertility decline (H1). We assumed that the onset of fertility decline began in Cairo and then spread to the Nile delta and lastly to the Nile valley (H2). Finally, we assumed that spatial diffusion occurs through the two traditional mechanisms of contagion diffusion and hierarchical diffusion (H3). In order to confirm our research hypotheses and reply to our research questions, we constructed several maps to study the geography of fertility decline (based on the CWR methods) both on a small scale and for a period of more than 50 years. These maps represent a total novelty in the study of Egyptian demography. Building on these maps, global and local spatial autocorrelation, we provided new insights into the decline in fertility in Egypt, while updating current knowledge on this subject. We have shown that Cairo is certainly not the only territory where the transition started before 1960 . We have also provided many distinctions concerning the two classical oppositions (urban/ rural and Lower/Upper Egypt), showing that fertility decline occurred very differently in such territories. Furthermore, we have decomposed the period of Egyptian fertility increase, highlighting that it did not affect all territories at the same rate or during the same period. Thus, despite its descriptive orientation, our study provides new evidence on the fertility transition in Egypt.

More specifically, we can state that our results partially confirm our hypothesis. First of all, the multiplicity of maps and the evolution of spatial autocorrelation leaves no doubt that there is a spatial diffusion of fertility control in Egypt (H1 and RQ1). This finding is consistent with the theoretical position of Casterline (2001), which highlighted the diffusion processes in the fertility transition. Additionally, it has been empirically illustrated in the literature on several periods and in different other countries (BocquetAppel \& Jakobi, 1997; Guilmoto \& Rajan, 2001; Potter et al., 2010; Schmertmann et al., 2008; Vitali \& Billari, 2017).

Secondly, our results highlight some original elements, particularly in the spatial pattern of this diffusion. Researchers often date the beginning of fertility decline in Egypt from the early 1960s onwards, and earlier in Cairo (H2). Our results provide some further distinctions regarding this finding (RQ2). We have shown that the fertility transition began before 1960 in some territories: Cairo, of course, but also Alexandria and other cities, and even some rural areas (around Zagazig and Tanta; countryside of Beni Mazar and Aswan). We have found some evidence that leads us to doubt the assumption that Cairo is ahead of the rest of the country. We highlighted that fertility transition may also have started in rural areas. While caution should be exercised in dating the onset of fertility decline in these rural areas, our results show that the process can begin elsewhere 
than in urban areas, as has been noted for some European fertility transitions (Bonneuil, 1997; Eggerickx et al., 2014).

We had assumed that the decline in fertility has been diffusing from the precursor territories to the Nile delta and then to the Nile valley with some delay, but our findings do not entirely correspond to this hypothesis. First, the precursor regions are located in both geographical areas. In addition, throughout the 1950s and 1960s, fertility decline occurred in both the valley and the Nile delta. For example, the main cities in the Nile valley did not lag behind those in the delta (except for Cairo and Alexandria). It was not until the early 1970s, during the increase of fertility, that a large part of the Nile valley lagged behind the Nile delta, with the exception of its cities.

Finally, in accordance with our third hypothesis (H3), we have highlighted two mechanisms of spatial diffusion (RQ3). Contagion diffusion (by geographic proximity) proved active throughout the fertility transition, particularly between urban and rural areas. Hierarchical diffusion occurred through the urban hierarchy: large cities began their fertility transition earlier than the medium-size ones, which themselves began earlier than the small towns. Of course, these two mechanisms combine and neither has primacy over the other.

Besides these elements, we have accurately described the spatial pattern of fertility decline in Egypt, which to our knowledge has never been done before. The literature has repeatedly highlighted that the transition of Egyptian fertility is exceptional compared to that of other countries, in particular with reference to the increase in fertility from the mid-1970s onwards and from 2008 onwards. Our results show the exceptionality of this transition with an overview of its spatial pattern. Indeed, while the characteristics of the spatial diffusion had been quite classical as from 1950, the process changed from 1971 to 1976. Compared to other known fertility transitions, Egypt's originality obviously lies in the fact that its transition stalled for several years, but mainly that this fertility increase affected the territories in different ways. The transition lasted for shorter of longer periods depending on the territory: it lasted less than 10 years in some places (especially in some part of the Nile delta) and more than 20 years elsewhere (mainly in rural areas of the Nile valley). In other words, in the middle of the Egyptian fertility transition, different territories showed contrasting trends for quite a long period: the fertility of some territories fell back into decline while the fertility of other territories increased. This variability in space and time between different territories can be observed during transition phases on a detailed scale; indeed, during a period of changes at the national level, variability can be observed at a detailed territorial level (Weeks, 2004). However, compared to other fertility transitions, in Egypt the stall and the subsequent increase in specific areas intensified this characteristic at different times. Our results are therefore original since they provide new information on this fertility increase. By describing in detail the spatial aspects of this period, we are able to propose adjustments to the studies based on the figures of fertility at national level.

We should point out that our study has some limitations. First, given our observation period (1950-2006) we were unable to analyse the transition of fertility in its entirety and the most recent trends. Then, we used two different data sources to estimate infant and child mortality in the governorates, which may constitute a bias in the estimation of CWRs. Finally, we did not consider the association between the analysed fertility trends 
and the socio-economic conditions of the different areas because off the difficulties to access space-time harmonized data. But this can be investigated in the future based on the results of this study. These descriptive findings may in fact provide a starting point for applying more advanced methods.

Despite the limitations, this study has led to some important findings and offers many starting points for future research. First of all, it takes an important place in the existing group of studies on spatial diffusion of fertility in developing countries where such kind of approach has been rarely adopted. Then, as previously highlighted, we added new elements of knowledge to the existing studies about fertility trends in Egypt by adopting a geographical approach to understand demographic phenomena. Indeed, we found that the spatial diffusion of fertility in Egypt is characterized by early transition (before 1960) in Cairo and other cities and even in few rural areas. Moreover, we found evidence of both propagation and hierarchical diffusion of fertility transition. Finally, our study contributes to in-depth knowledge of a demographic dynamic which is fundamental for the future of the Egyptian population. A detailed knowledge of fertility patterns on a fine scale is also relevant because family programs and policies targeting fertility can be more efficient when developed at the local level.

\section{Annex 1}

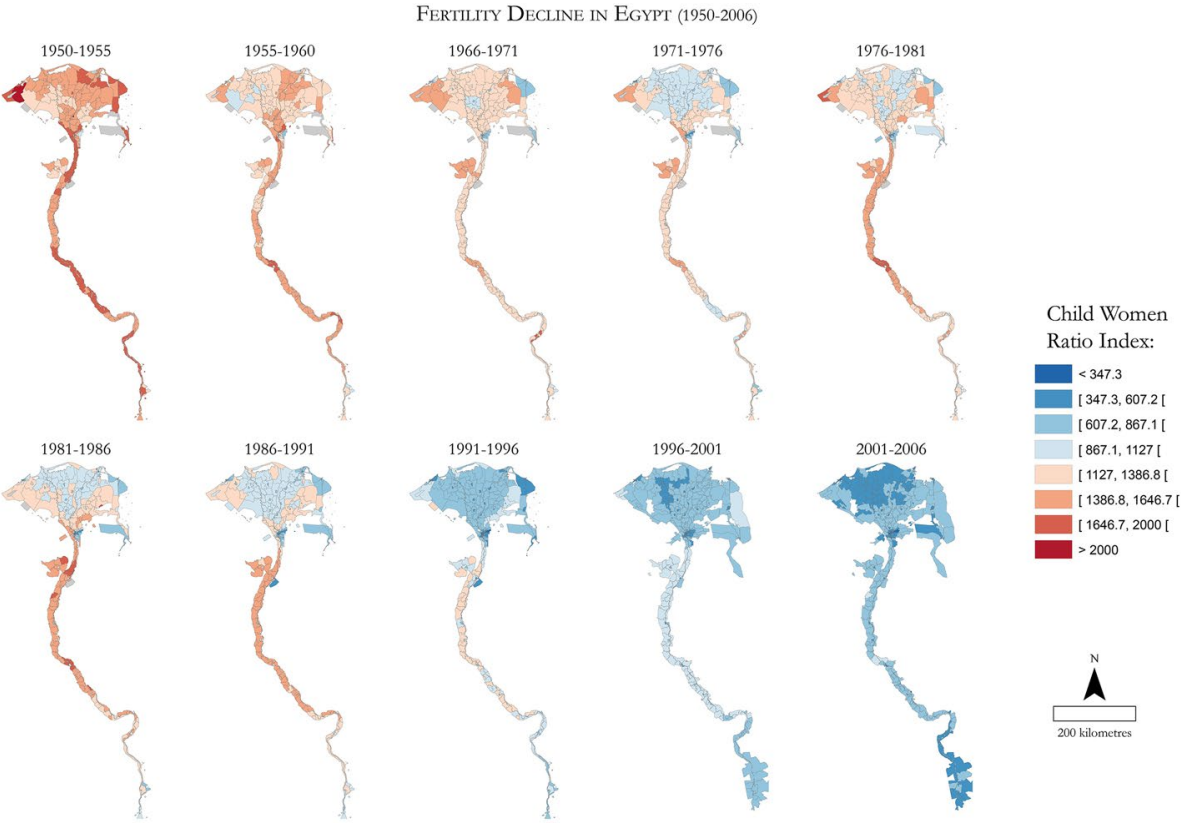




\section{Annex 2}

Fertility Decline in the Nile Delta (1950-2006)
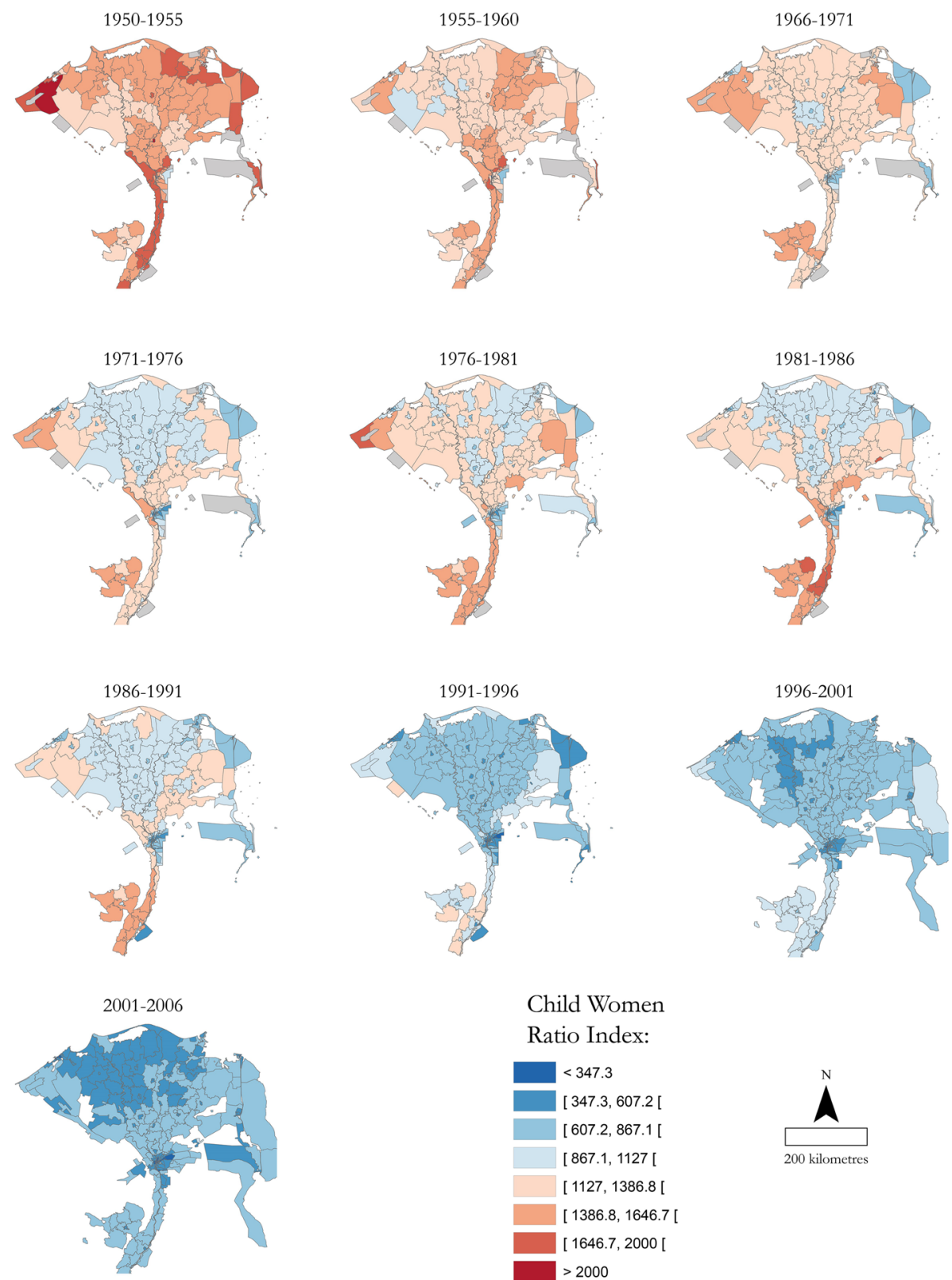

Child Women Ratio Index:
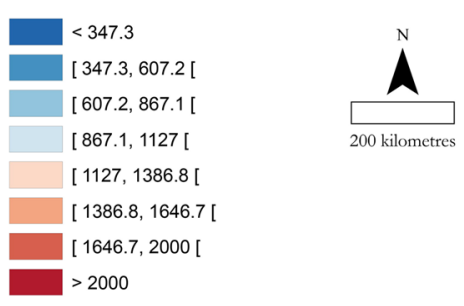


\section{Annex 3}

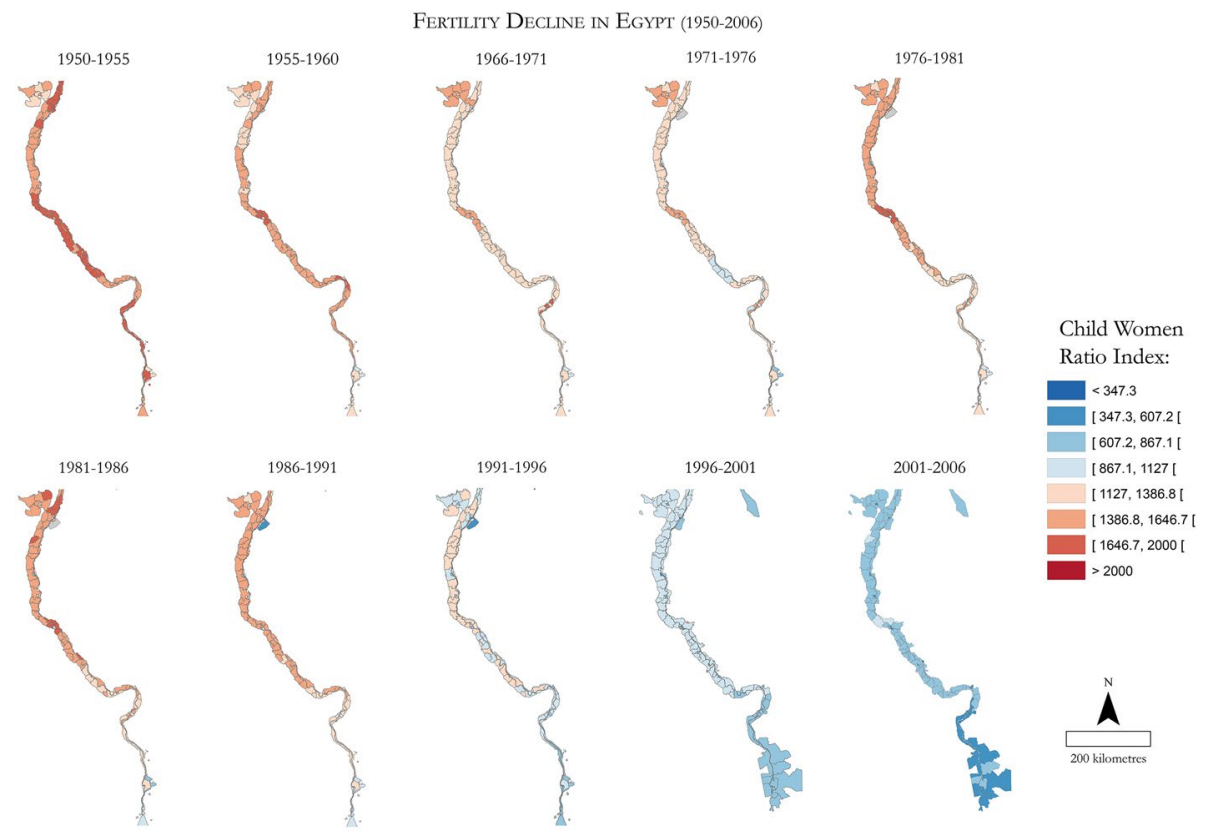

Acknowledgements

We thank Karine Bennafla and Hala Bayoumi of the CEDEJ for all their discussions and advice. We would also like to thank Mr. Muntaser of CAPMAS for his help and knowledge of administrative changes.

\section{Authors' contributions}

YD contributed to the development of the research questions, performed the statistical analysis, designed the maps and wrote the "Materials and methods" and "Results" sections of the article. EA contributed to the development of the research questions, developed with SM the introduction, the discussion and conclusion and also helped with the interpretation of the results. SM contributed to the development of the research questions and to writing the "Background and literature review" section and conclusion, supervised the analysis and was in charge of the revision of the drafts and the final version of the article. All authors read and approved the final manuscript.t.

\section{Funding}

Funding provided by the Fondation Maison des Sciences de I'Homme through its ATLAS postdoctoral mobility program and by the University of Rome La Sapienza H2020 Grant "EUMED relations: cooperation, borders and migration" (no. PH11715C7E20DCEC).

\section{Availability of data and materials}

Not applicable.

\section{Declarations}

\section{Competing interests}

The authors declare that they have no conflict of interest.

\section{Author details}

${ }^{1}$ Centre for Demographic Research, UCLouvain, Institute for the Analysis of Change in Contemporary and Historical Societies, 1, Place Montesquieu, Boîte L2.08.03, 1348 Louvain-la-Neuve, Belgium. ${ }^{2}$ Department of Methods and Models for Economics, Territory and Finance, Sapienza University of Rome, Via del Castro Laurenziano, 9-00161 Rome, Italy.

Received: 30 March 2021 Accepted: 9 August 2021

Published online: 22 September 2021

\section{References}

Al Zalak, Z., \& Goujon, A. (2017). Exploring the fertility trend in Egypt. Demographic Research, 37(32), 995-1030. https://doi. org/10.4054/DemRes.2017.37.32 
Ambrosetti, E. (2011). Égypte, l'exception démographique. Institut National d'Études Démographiques.

Ambrosetti, E. (2014). Égypte, la natalité repart à la hausse. Orient XXI. http://orientxxi.info/magazine/egypte-la-nataliterepart-a-la-hausse,0537

Anselin, L. (1988). Spatial econometrics: Methods and models. Kluwer Academic Publishers.

Anselin, L. (1995). Local Indicators of Spatial Association-LISA. Geographical Analysis, 27(2), 93-115. https://doi.org/10 $1111 / j .1538-4632.1995 . t b 00338 . x$

Anselin, L. (1996). The Moran scatterplot as an ESDA tool to assess local instability in spatial association. In M. Fischer, H. K. Scholten, \& D. Unwin (Eds.), Spatial analytical perspectives on GIS (pp. 111-125). Taylor \& Francis.

Assembly of Behavioral and Social Sciences, National Research Council (Ed.). (1982). The estimation of recent trends in fertility and mortality in Egypt. National Academy Press.

Awadalla, N. (2017). Egypt promotes birth control to fight rapid population growth. Reuters. https://www.reuters.com/ article/us-egypt-population/egypt-promotes-birth-control-to-fight-rapid-population-growth-idUSKCN1BA153.

Basten, S., Huinink, J., \& Klüsener, S. (2012). Spatial Variation of Sub-national Fertility Trends in Austria, Germany and Switzerland. Comparative Population Studies, 36(2-3). http://www.comparativepopulationstudies.de/index.php/CPoS/ article/view/79.

Bleha, B., \& Ďurček, P. (2017). An interpretation of the changes in demographic behaviour at a sub-national level using spatial measures in post-socialist countries: A case study of the Czech Republic and Slovakia. Papers in Regional Science, 98(1), 331-351. https://doi.org/10.1111/pirs.12318

Bocquet-Appel, J.-P., \& Jakobi, L. (1997). Diffusion spatiale de la contraception en Grande-Bretagne, à l'origine de la transition. Population, 52(4), 977-1003. https://doi.org/10.2307/1534621

Bocquet-Appel, J.-P., \& Jakobi, L. (1998). Evidence for a spatial diffusion of contraception at the onset of the fertility transition in Victorian Britain. Population, 10(1), 181-204. https://doi.org/10.2307/1534621

Bonneuil, N. (1997). Transformation of the French demographic landscape, 1806-1906. Oxford University Press.

Bonneuil, N., \& Dassouki, C. (2006). Women's education and diffusion of the fertility transition: The case of Egypt 1960-1996 in 4905 administrative subdivisions. Journal of Population Research, 23(1), 27-39.

Brunsdon, C., Fotheringham, A. S., \& Charlton, M. E. (1996). Geographically weighted regression: A method for exploring spatial nonstationarity. Geographical Analysis, 28(4), 281-298.

Caldwell, J. C. (1986). Routes to low mortality in poor countries. Population and Development Review, 12(2), 171-220. https://doi.org/10.2307/1973108

Casterline, J. B. (Ed.). (2001). Diffusion processes and fertility transition: selected perspectives. National Academy Press.

Chesnais, J.-C. (1992). The demographic transition: stages, patterns, and economic implications. Clarendon Press: Oxford University Press.

Cleland, J., \& Wilson, C. (1987). Demand theories of the fertility transition: An iconoclastic view. Population Studies, 41(1), 5-30. https://doi.org/10.1080/0032472031000142516

Coale, A. J., \& Watkins, S. C. (1986). The decline of fertility in Europe. Princeton University Press.

Costa, R. (2015). Diffusion effects in the Belgian fertility transition. Space-time analyses at the municipal and individual levels (1887-1934) [Ph.D. in Demography]. Université Catholique de Louvain.

Courbage, Y. (1994). La politique démographique en Égypte et son évaluation. Que nous apprennent les enquêtes récentes ? Population, 49(4-5), 1041-1055. https://doi.org/10.2307/1533668.

Courbage, Y. (1999). Nouveaux horizons démographiques en Méditerranée. Institut National d'Etudes DémographiquesPresses Universitaires de France.

Courbage, Y. (2015a). Egypte, une transition démographique en marche arrière. Orient XXI. http://orientxxi.info/magazine/ egypte-une-transition-demographique-en-marche-arriere,0956

Courbage, Y. (2015b). The political dimensions of fertility decrease and family transformation in the Arab context. DIFI Family Research and Proceedings, 2015(3), 15. https://doi.org/10.5339/dif.2015.3

De Castro, M. C. (2007). Spatial demography: An opportunity to improve policy making at diverse decision levels. Population Research and Policy Review, 26(5-6), 477-509. https://doi.org/10.1007/s11113-007-9041-x

Denis, E., \& Moriconi-Ebrard, F. (1998). La population de I'Egypte 1897-1996. Linformation Géographique, 62(1), 12-23. https://doi.org/10.3406/ingeo.1998.2564

Eggerickx, T., Sanderson, J.-P., \& Costa, R. (2014). La fécondité des populations rurales en Belgique (1880-1940). Des comportements très diversifiés. Espace Populations Sociétés, 2014/1,23. https://doi.org/10.4000/eps.5684

Fargues, P. (1997). State policies and the birth rate in Egypt: From socialism to liberalism. Population and Development Review, 23(1), 115-138. https://doi.org/10.2307/2137463

Fargues, P. (2002). La population de l'Egypte au XXe : une évolution déconcertante. In J.-C. Chasteland \& J.-C. Chesnais (Eds.), La population du monde: géants démographiques et défis internationaux (Institut National d'Etudes Démographiques-Presses Universitaires de France, pp. 171-196). INED. https://books.google.fr/books?hl=fr\&lr=\& $\mathrm{id}=$ Qvrc3X3792gC\&oi=fnd\&pg =PA1\&dq=les+populations + du + monde $+:+\mathrm{g} \%$ C3\%A9ants+d\%C3\%A9mographi ques+et+d\%C3\%A9fis+internationaux\&ots=OMHJVU9yg0\&sig=4LCMGK5adqQ4y/4JNHCTWMt6mt8

Fargues, P. (2003). La femme dans les pays arabes : Vers une remise en cause du système patriarcal ? Population Et Sociétés, $4,387$.

Goldstein, J. R., \& Klüsener, S. (2014). Spatial Analysis of the Causes of Fertility Decline in Prussia. Population and Development Review, 40(3), 497-525. https://doi.org/10.1111/j.1728-4457.2014.00695.x

Guilmoto, C. Z., \& Rajan, S. I. (2001). Spatial patterns of fertility transition in Indian districts. Population and Development Review, 27(4), 713-738. https://doi.org/10.1111/j.1728-4457.2001.00713.x

Klüsener, S., Dribe, M., \& Scalone, F. (2019). Spatial and social distance at the onset of the fertility transition: Sweden, 1880-1900. Demography, 56(1), 169-199. https://doi.org/10.1007/s13524-018-0737-9

Krafft, C. (2020). Why is fertility on the rise in Egypt? The role of women's employment opportunities. Journal of Population Economics, 33(4), 1173-1218. https://doi.org/10.1007/s00148-020-00770-w

Kurek, S., \& Lange, M. (2012). Urbanisation and changes in fertility pattern in Poland and in the selected countries of Western and Southern Europe. Bulletin of Geography. Socio-Economic Series, 17(17), 2012. https://doi.org/10.2478/ v10089-012-0008-2 
Lee, J., Lay, J.-G., Chin, W. C. B., Chi, Y.-L., \& Hsueh, Y.-H. (2014). An Experiment to Model Spatial Diffusion Process with Nearest Neighbor Analysis and Regression Estimation. International Journal of Applied Geospatial Research, 5(1), 1-15.

Pagès-El Karoui, D. (2012). Géographie du changement social en Égypte. EchoGéo, 21, 32. https://doi.org/10.4000/echog eo.13204

Potter, J. E., Schmertmann, C. P., Assunção, R. M., \& Cavenaghi, S. M. (2010). Mapping the timing, pace, and scale of the fertility transition in Brazil. Population and Development Review, 36(2), 283-307.

Rashad, H. (2015). The tempo and intensity of marriage in the Arab region: Key challenges and their implications. DIF Family Research and Proceedings, 2015(2), 18. https://doi.org/10.5339/difi.2015.2

Rashad, H., \& Zaky, H. (2014). A comparative analysis of fertility plateau in Egypt, Syria and Jordan: policy implications. In ICPD Beyond 2014 Arab States Report: Development Challenges and Population Dynamics in a Changing Arab World (pp. 265-302). LAS, UNFPA,ESCWA, UNECA. schools.aucegypt.edu/research/src/Documents/Fertility_Plateau/A Comparative Analysis of Fertility Plateau.pdf

Sabater, A., \& Graham, E. (2019). International migration and fertility variation in spain during the economic recession: a spatial durbin approach. Applied Spatial Analysis and Policy, 12(3), 515-546. https://doi.org/10.1007/ s12061-018-9255-9

Saint-Julien, T. (2007). The process of spatial diffusion and modeling change. In L. Sanders (Ed.), Models in spatial analysis (pp. 127-157). ISTE Ltd.

Schmertmann, C. P., Potter, J. E., \& Cavenaghi, S. M. (2008). Exploratory Analysis of Spatial Patterns in Brazil's Fertility Transition. Population Research and Policy Review, 27(1), 1-15. https://doi.org/10.1007/s11113-007-9052-7

Vitali, A., Aassve, A., \& Lappegård, T. (2015). Diffusion of childbearing within cohabitation. Demography, 52(2), 355-377. https://doi.org/10.1007/s13524-015-0380-7

Vitali, A., \& Billari, F. C. (2017). Changing Determinants of Low Fertility and Diffusion: A Spatial Analysis for Italy. Population Space and Place, 23(2), e1998. https://doi.org/10.1002/psp.1998

Watkins, S. C. (1991). From provinces into nations: demographic integration in Western Europe, 1870-1960. Princeton University Press. http://site.ebrary.com/id/10900066.

Weeks, J. R. (2004). The role of spatial analysis in demographic research. In M. F. Goodchild \& D. G. Janelle (Eds.), Spatially integrated social science (pp. 381-399). Oxford University Press.

Weeks, J. R. (2010). Spatial patterns of fertility in rural Egypt. In L. Anselin \& S. J. Rey (Eds.), Perspectives on spatial data analysis (pp. 235-256). Springer.

Weeks, J. R., Gadalla, M. S., Rashed, T., Stanforth, J., \& Hill, A. G. (2000). Variability in fertility in Menoufia, Egypt, assessed through the application of remote-sensing and GIS technologies. Environment and Planning A. https://doi.org/10. 1068/a3286

Weeks, J. R., Getis, A., Hill, A. G., Gadalla, M. S., \& Rashed, T. (2004). The fertility transition in Egypt: Intraurban patterns in Cairo. Annals of the Association of American Geographers, 94(1), 74-93. https://doi.org/10.1111/j.1467-8306.2004. 09401005.x

\section{Publisher's Note}

Springer Nature remains neutral with regard to jurisdictional claims in published maps and institutional affiliations.

\section{Submit your manuscript to a SpringerOpen ${ }^{\circ}$ journal and benefit from:}

- Convenient online submission

- Rigorous peer review

- Open access: articles freely available online

- High visibility within the field

- Retaining the copyright to your article

Submit your next manuscript at $\boldsymbol{\nabla}$ springeropen.com 